

\section{GEOLOGICAI SURVEY CIRCULAR 405}

\section{ERRATA}

Page 10, last paragraph should read:

"Size, weight and ruggedness-For field use an altimeter should be convenient to carry over difficult terrain...."

Page 13, top of left-hand column should read:

*....connections do not move appreciably, the stress on the diaphragrams changes considerably with extreme variations in atmospheric pressure, as can be seen in figure 9. The barostat, previously described, can be con sidered an instrument of the null type in which the altitude measurements are based on weights rather than spring movement." 
UNITED STATES DEPARTMENT OF THE INTERIOR

FRED A. SEATON, Secretary

GEOLOGICAL SURVEY

Thomas B. Nolan, Director

GEOLOGICAL SURVEY CIRCULAR 405

\title{
INSTRUMENTAL IMPROVEMENTS IN ALTIMETRY
}

\author{
By James L. Buckmaster and Atherton H. Mears
}

Washington, D. C., 1958

Free on application to the Geological Survey, Washington 25, D. C. 



\section{CONTENTS}

Abstract............................... 1

Use of altimetry by the Geological Survey . . . . . . . . . . . . . . . . . . 1

Accuracy attainable with present instruments and methods . . . . . . . . . . . . . 2

Sources of error. ........................... 2

Geological Survey instrumental experience. . . . . . . . . . . . . . . 3

Characteristics of an ideal surveying altimeter . . . . . . . . . . . . . . 7

Considerations in altimeter design. . . . . . . . . . . . . . . . . 11

Pressure-sensitive element. . . . . . . . . . . . . . . . . . 11

Freedom from constraints. . . . . . . . . . . . . . . . . . . 11

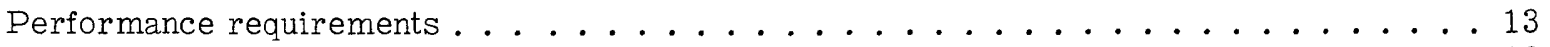

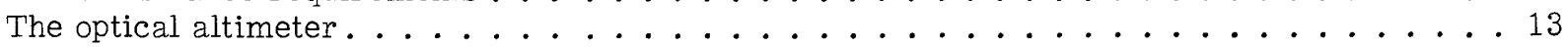

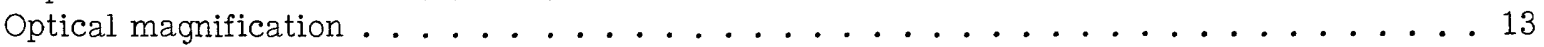

Experimental optical altimeters . . . . . . . . . . . . . . . . . . 14

Performance of experimental models. . . . . . . . . . . . . . . . 20

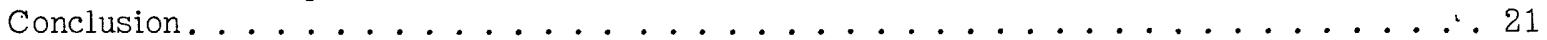

Appendix A. The air density correction factor in altimetry . . . . . . . . . . . 23

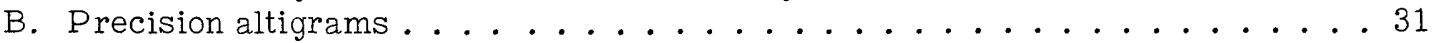

C. A method for calibrating altimeters. . . . . . . . . . . . . . 32

D. Strain in flexural elements. . . . . . . . . . . . . . . 33

\section{ILLUSTRATIONS}

Figure 1. Nomogram for obtaining air temperature and relative humidity correction factor . . 2

2. Variations in barometric gradient during a field test ............. 3

3. Schematic diagram of barostat ..................... . . 4

4. Barostat (right) and test chamber with manifold system (left) . . . . . . . . . 5

5. A. Sensitive unit of barostat; B. Weights for barostat . . . . . . . . . . 6

6. Calibration curves for service altimeter $\mathrm{T}-25270 \ldots \ldots \ldots \ldots$

7. Temperature correction curve for a service altimeter . . . . . . . . . . 7

8. Generalized graph of change in elastic error with time and stress . . . . . . . . 9

9. Cross-sectional diagram of vacuum box in null-type altimeter . . . . . . . . 13

10. Schematic diagram of direct-reading optical altimeter. . . . . . . . . . . . 13

11. Schematic diagram of tilting-mirror optical altimeter. . . . . . . . . . . 14

12. Experimental optical altimeter, model X-2 . . . . . . . . . . . . . 15

13. Experimental optical altimeter, model X-1 . . . . . . . . . . . . . 15

14. View of model $X-2$ with case removed, looking toward objective . . . . . . . . 16

15. View of model X-2 with case removed, looking toward mirror . . . . . . . . . . 17

16. Calibration correction curves for optical altimeter $\mathrm{X}-1$ and service altimeter $\mathrm{T}-25270 \ldots \ldots \ldots \ldots$

17. Cross-sectional diagram of lighting unit for tilting-mirror optical altimeter. . . . 19

18. Corrections to air density factors for lower base readings below 5,000 . . . . . 27

19. Corrections to air density factors for lower base readings above 5,000 . . . . 28

20. Electronic altigraph records . . . . . . . . . . . . . . 31

21. Strain in curved flexural element. . . . . . . . . . . . . . 33 


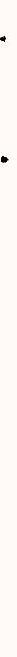




\title{
INSTRUMENTAL IMPROVEMENTS IN ALTIMETRY
}

\author{
By James L. Buckmaster and Atherton H. Mears
}

\begin{abstract}
The Topographic Division of the Geological Survey has conducted a research program in altimetry since 1954 in an effort to improve the accuracy of the method so that it can be used more widely to provide control elevations for photogrammetric mapping. Results of this research include the construction of a barostat, to provide an improved calibration standard, and the design and construction of experimental altimeters that use optical instead of mechanical magnification in measuring the displacement of the pressure-sensitive element.
\end{abstract}

\section{USE OF ALTIMETRY BY THE GEOLOGICAL SURVEY}

Altimetry for determining elevations above sea level ${ }^{1}$ has been used in the Geological Survey from the time of its foundation. In fact, the "Second Annual Report of the United States Geological Survey, 1880-81, " contains an outstanding article on the subject by Dr. G. K. Gilbert, then chief geologist; although the instrumental references are now obsolete, the theoretical treatment of physical considerations and errors is classical.

As applied to the operations of the Topographic Division of the Survey, altimetry was an indispensable source of control elevations for reconnaissance mapping before 1900. However, as more rigid standards of accuracy were adopted, spirit leveling, planetable stadia traverse, and precise trigonometric leveling largely supplanted altimetry as a means of supplying control elevations.

\footnotetext{
1 In the present paper, the term "elevation" will be used exclusively for heights referred to sea-level datum. "Bltitude" will be used in referring to uncorrected readings of the altimeter or to vertical changes that are not specifically correlated with sea-level datum.
}

Compliance with the vertical-accuracy specifications of the National Map Accuracy Standards requires that at least 90 percent of the points tested shall be accurate within onehalf of the contour interval. To meet this standard with the photogrammetric methods and procedures now employed, elevations used to control aerial photographs are required to be accurate within the following limits:

$\begin{array}{cr}\begin{array}{c}\text { Contour interval } \\ \text { (feet) }\end{array} & \begin{array}{r}\text { Error li } \\ \text { photocontrol } \\ \text { (feet) }\end{array} \\ 5 & 0.5 \\ 10 & 1.0 \\ 20 & 2.0 \\ 25 & 2.5 \\ 40 & 3.0 \\ 50 & 4.0 \\ 80 & 5.0\end{array}$

Stadia traverse with planetable and alidade can supply photocontrol elevations for mapping at any of these contour intervals. Precise vertical-angle observations may be used to control mapping at contour intervals of 20 feet or larger. Both of these methods include checks on the observations and ties to 
higher order control so that the accuracy of the results can be evaluated with certainty. However, they involve laborious and expensive fieldwork, particularly in remote or heavily wooded areas.

The speed and ease with which altimeter surveys can be carried out offers an attractive possibility for lowering the costs of supplemental control, provided that acouracy standards can be met. Altimetry has been successfully used to control mapping at contour intervals of 40 feet and larger despite the fact that tests have disclosed anomalous errors of 5 and 6 feet in the results of even the most carefully executed altimeter surveys. The effect of these overlarge errors has been minimized by obtaining a considerable surplus of elevations so that the photogrammetrist can eliminate obviously incorrect elevations and apply an averaging technique in leveling the stereomodels.

The altimetry research program of the Topographic Division has been directed toward eliminating anomalous errors and increasing the absolute accuracy of the instruments. Obviously, if elevations reliable within 1 or 2 feet can be obtained by altimetry, the method can be used to control standard-accuracy photogrammetric mapping at contour intervals of 20 and possibly 10 feet. The results thus far obtained from the research program indicate that a redesign of the altimeter will be the greatest single factor in reducing the magnitude of errors in elevations determined by altimeter surveys. In addition, more frequent and precise calibration will provide better calibration corrections. Also, it is evident that altimeter surveys should not be undertaken when weather conditions are unstable.

\section{ACCURACY ATTAINABLE WITH PRESENT INS'TRUMENTS AND METHODS}

Sources of error

Before discussing the possible improvements in altimeters that have been pointed up by the research to date (1958), the fundamental causes of errors in altimetry should be reviewed.

Instrumental errors. --Errors inherent in the altimeter itself will be described below, in the sections concerned with altimeter characteristics and design. These errors at present contribute an indeterminate part of the net error and complicate the analysis of other effects. At times, instrumental error exceeds that due to atmospheric variations and hence is a limiting factor, especially when atmospheric conditions are favorable.

Atmospheric and gravitational irregularities. --Variations in air temperature over the area being surveyed are difficult to determine and may cause large errors unless the influence of local conditions (such as wind, timber, and clearings) is taken into account. Humidity has a much smaller effect and therefore does not need to be measured with the same precision as temperature. Below $85^{\circ} \mathrm{F}$, humidity corrections are small, and they become negligible below $40^{\circ} \mathrm{F}$. The nomogram shown in figure 1 clearly illustrates the relative effects of temperature and humidity and provides a convenient means for determining the correction factor for the combined effect of these two conditions. This correction factor is the reciprocal of air

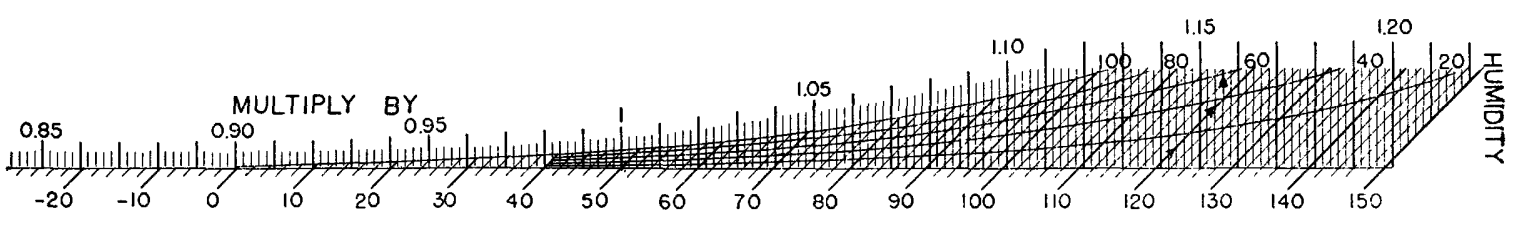

Figure 1.--Nomogram for obtaining air temperature and relative humidity correction factor. Courtesy Wallace \& Tiernan, Inc. 
density. In the two-base method of altimetry, air density and the correction factor are determined through the use of high- and low-base altimeter readings, eliminating the need for field measurements of temperature and humidity. (See App. A.)

Barometric gradients can be accurately determined only by using an array of three or more base stations. ${ }^{2}$ As errors caused by atmospheric circulation are difficult, sometimes impossible, to estimate, altimeter surveys should not be undertaken in high winds. Figure 2 shows by vectors the magnitude and variation of the barometric gradient during a field test conducted under good weather conditions. Examples of local disturbances can be seen in the barograms, figure 20 (App. B).

Corrections for errors due to the variations of gravity are usually negligible but may be obtained from the Smithsonian tables if desired.

Observational errors and mistakes. -Mistakes or blunders, such as reading the wrong division, can be avoided by using proper care in reading the instrument; errors of interpolation, however, are caused by the limitations of perception. The design of the instrument has a definite influence on both mistakes and errors. Fewer mistakes will occur if the altimeter is well designed in graduations and numbering, is well illuminated, and is convenient to use. An optical reading system can minimize errors of observation through reduced parallax and increased magnification.

Calibration. --When the limit of tolerable error for an altimeter is set at 1 foot, as it must be if the instrument is to be widely used for obtaining supplemental photocontrol elevations, the methods of calibration now in common use are inadequate. To disclose instrumental changes that may occur through field use, service altimeters should be calibrated before and after each major project.

\footnotetext{
${ }^{2}$ Mears, A. H., and Haring, W. F., 1954, Multiple-base altimetry: Photogramm. Eng., v. 20, no. 5, p. 814-22.
}

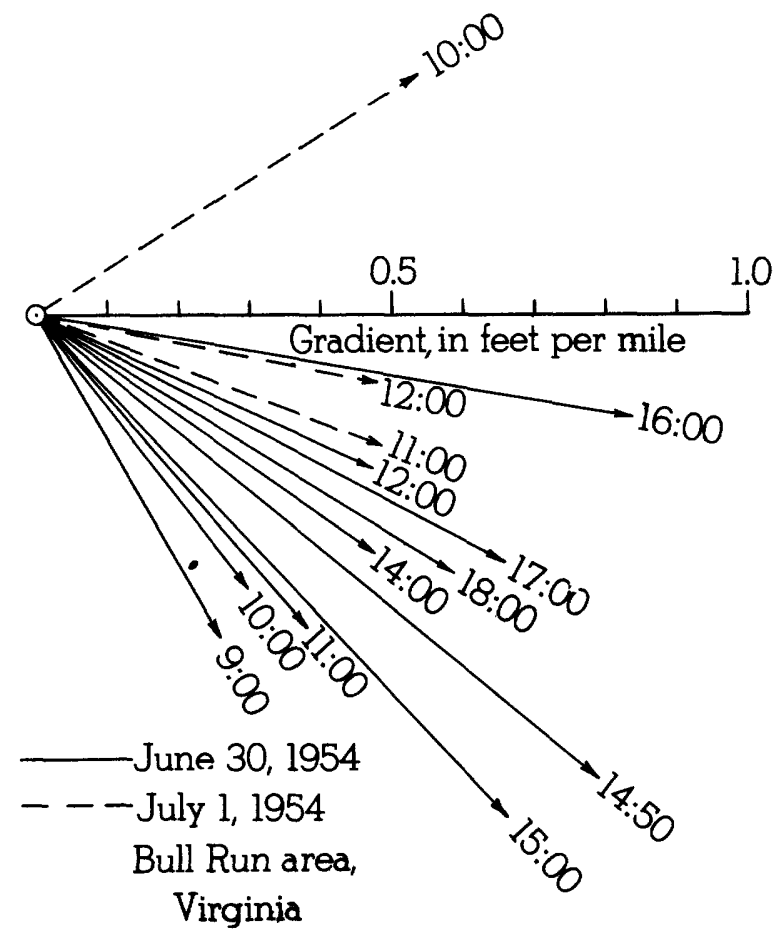

Figure 2.--Variations in barometric gradient during a field test.

The method of calibration formerly used by the Geological Survey consisted in comparing sets of six or more altimeters in a test chamber, at successive pressure intervals that correspond approximately to even 100foot steps of elevation. (See App. C.) Calibration with mercurial standards is impractical because it requires mercurials of high precision and expert operators and is prohibitively expensive. Calibration with a precise laboratory aneroid standard is reasonably fast and convenient; but neither this nor the other methods previously mentioned will provide the accuracy now sought. To provide an adequate calibration standard, the Survey has constructed a barostat, which will be described in detail below.

Geological Survey instrumental experience

It should be possible to determine elevations of field stations with an average error of less than 2 feet if the following conditions are met: 
Atmospheric conditions are favorable.

The altimeters are highly accurate; that is, the sum of instrumental and observational error does not exceed 1 foot.

The area of survey is limited to a radius of 10 miles.

The difference in elevation between any base and any field station is less than 2,000 feet. This requirement is based on the general assumption that error due to atmospheric anomalies is proportional to the difference in elevation. With the weather favorable and operations limited to a 10-mile radius, error due to atmospheric variations is estimated to average $1 / 1000$ of the difference in elevation.

Results of test survey at Bull Run. -On June 30 and July 1, 1954, a test field survey was carried out in the Bull Run Mountains near
Middleburg, Va. The results of this limited test demonstrate the accuracy that can be obtained in field elevations when the ideal conditions listed above are approximated.

In this test, the difference in elevation between the highest and lowest field stations was about 450 feet. All field stations were within 250 feet of the average elevation of the three base stations. At the base stations, the range in altitude readings due to barometric changes amounted to less than 50 feet. Two altigraphs and four surveying altimeters were used. The two altigraphs were used at base stations; their charts could be read to 0.1 foot, and the indicated altitude changes were accurate to 0.5 foot. The survey altimeter at the third base station had no irregularities in its calibration curve for the range of pressures encountered; the altitude readings from this instrument were accurate within the observational limit of 1 foot.

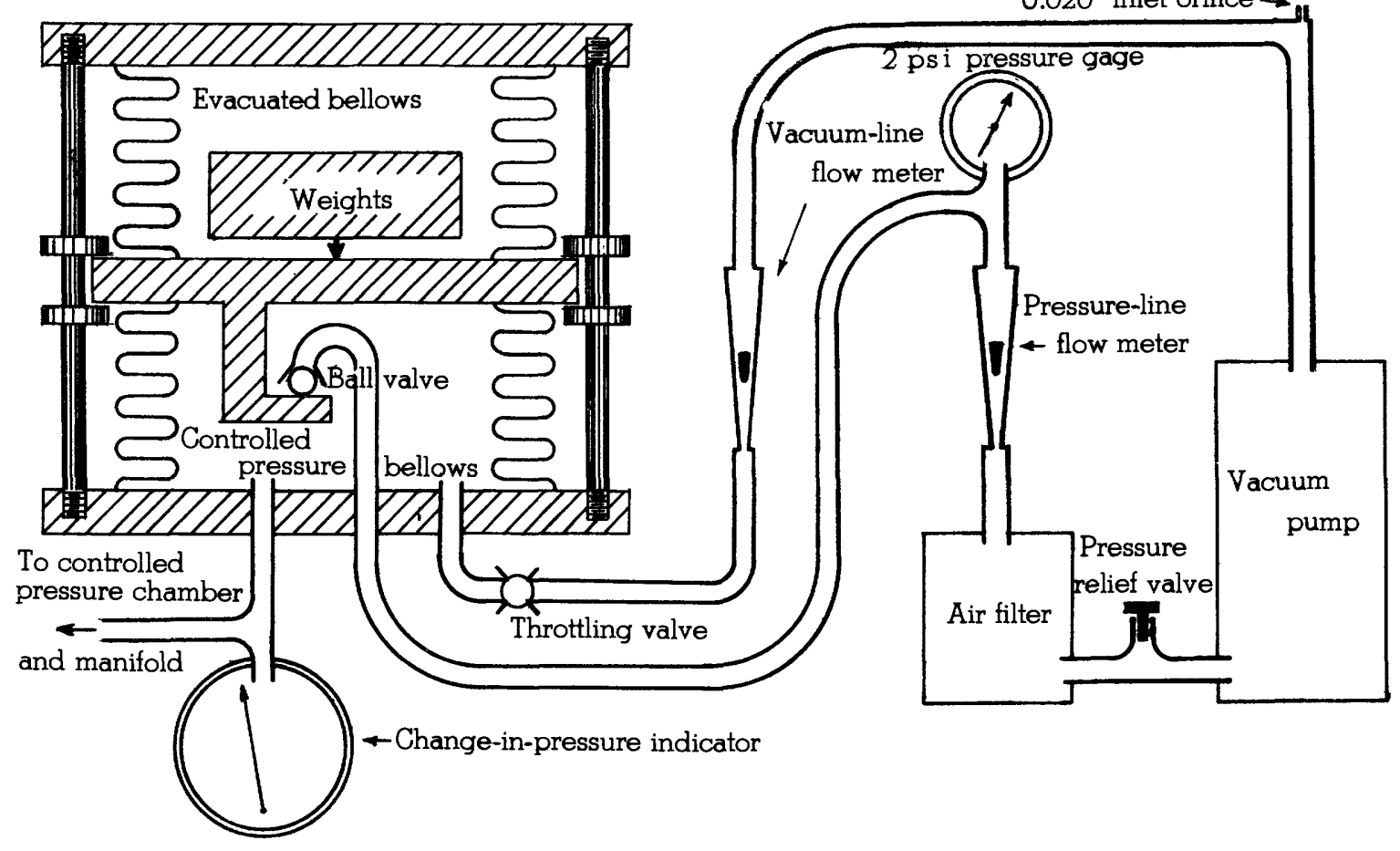

Figure 3. --Schematic diagram of barostat. 
Atmospheric conditions on July 1 were especially favorable for the test survey. Low wind velocities made it possible to obtain accurate measurements of temperature and humidity over the entire survey area. (Light winds tend to make air density more uniform and also to nullify unequal heating effects caused by solar radiation.) The roving altimeters were used to determine elevations on 12 field stations, of which 11 were bench marks and the twelfth was a road intersection with an elevation previously established by stadia traverse. The average error of the elevations determined by altimetry was 1.3 feet.

One of the altimetric elevations, however, was in error by 6 feet. The service altimeter in question was later subjected to repeated calibrations, at 10 -foot intervals, over the portion of its scale used in the field test. These detailed calibrations revealed an abrupt change in the instrument's calibration curve; when the true calibration correction was applied, the error of the elevation was reduced to 1 foot. It can thus be inferred that, when high accuracy is required, the present service altimeters may have to be calibrated at intervals smaller than 100 feet. Such detailed calibration can be very laborious.

The barostat. --To provide a more accurate and convenient calibration standard for altimeters, a modified version of the Johnson barostat designed at the National Bureau of

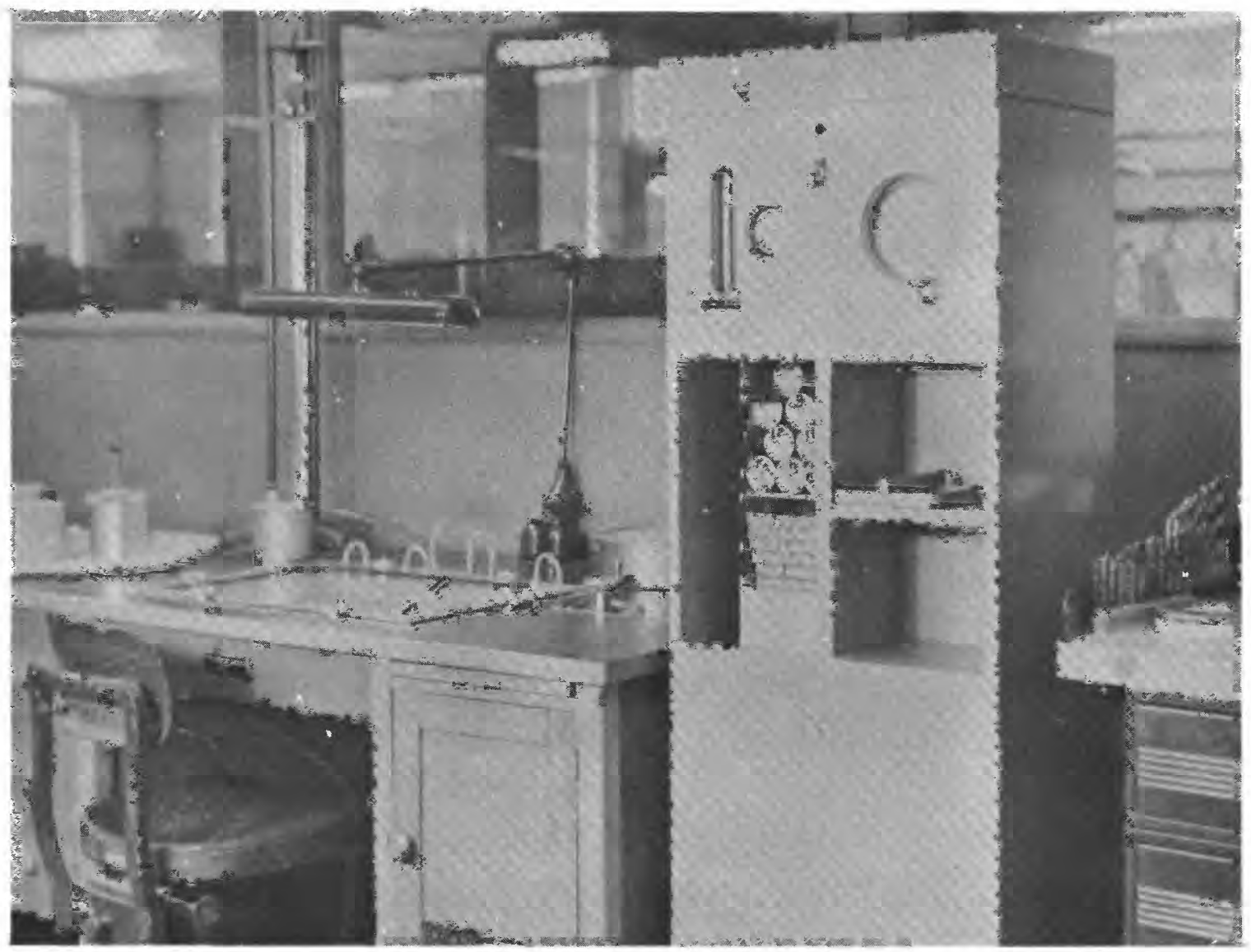

Figure 4. --Barostat (right) and test chamber with manifold system (left). 
Standards has been constructed in the instrument shop of the Geological Survey at Silver Spring, Md. (See figs. 3, 4, 5.) The testchamber pressure is regulated by a set of precisely computed and machined weights, which produce absolute pressure intervals equivalent to 100 -foot steps of elevation. The term "absolute" is used conditionally because 1 -foot absolute accuracy in altimetry is an elusive goal. Pressure datum for the barostat is established by comparison with a highly precise laboratory aneroid calibrated by the Bureau of Standards. Inasmuch as the elevation datum for field altimeter surveys is established by placing the base stations at bench marks, a slight difference between the pressure datum of the barostat and true sea-level pressure datum is not important.

The barostat is fast and relatively simple in operation and provides far more accurate and repeatable test-chamber pressures than any method of calibration used heretofore. Calibration with the barostat is expected to improve the results of altimetry substantially, by indicating the reliability of each service altimeter as well as by providing more accurate calibration corrections. Aneroid hysteresis is apparent from the calibration data because the barostat itself is virtually free of hysteresis and operates on an absolute rather than a comparative basis. Figure 6 illustrates the difference between the calibration curves for a service altimeter obtained by comparison with nine other service altimeters (dotted line) and by the use of the barostat (dashed line). Field tests have not yet been made to determine what effect calibration with the barostat has had on the accuracy of field elevations.

General conclusions. --The results of regular supplemental control projects with altimeters, as well as laboratory research, indicate that the greatest need is for higher absolute accuracy in service altimeters, though the use of the barostat for calibration can be expected to bring about some improvement in the accuracy of field elevations. The sensitivity of present altimeters is adequate and should not be confused with absolute accuracy.

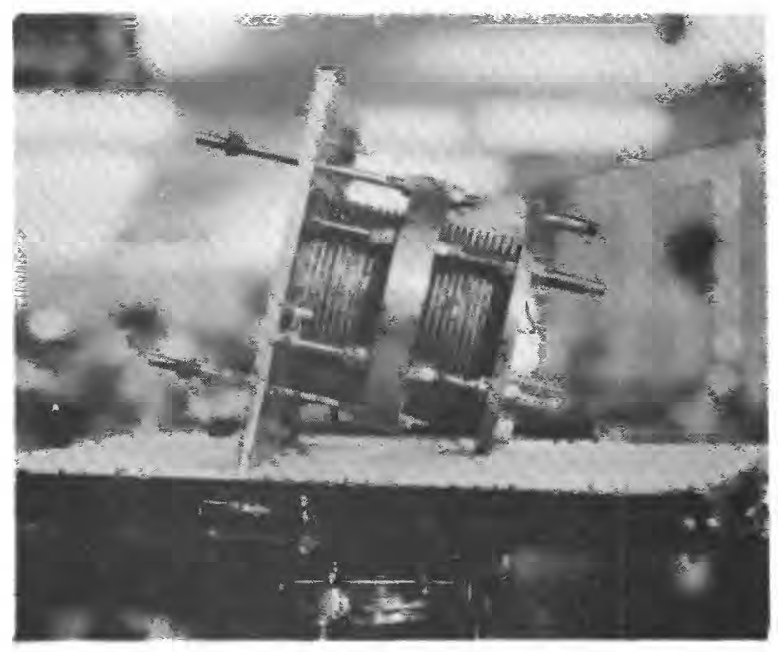

A

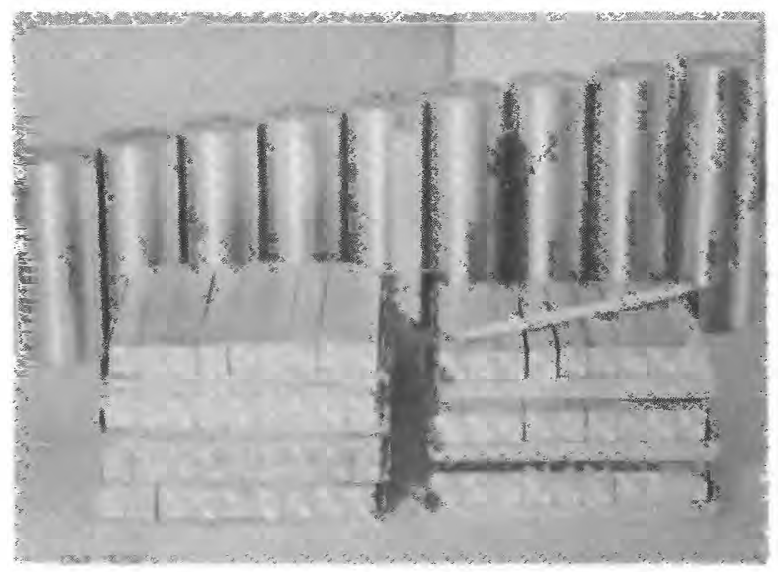

B

Figure 5. --A. Sensitive unit of barostat; B. Weights for barostat.

Daily field comparison of the six or more altimeters used on a supplemental control project usually disclose unaccountable differences of several feet between instruments. A part of each of these discrepancies is assumed to be caused by the limitations of field 


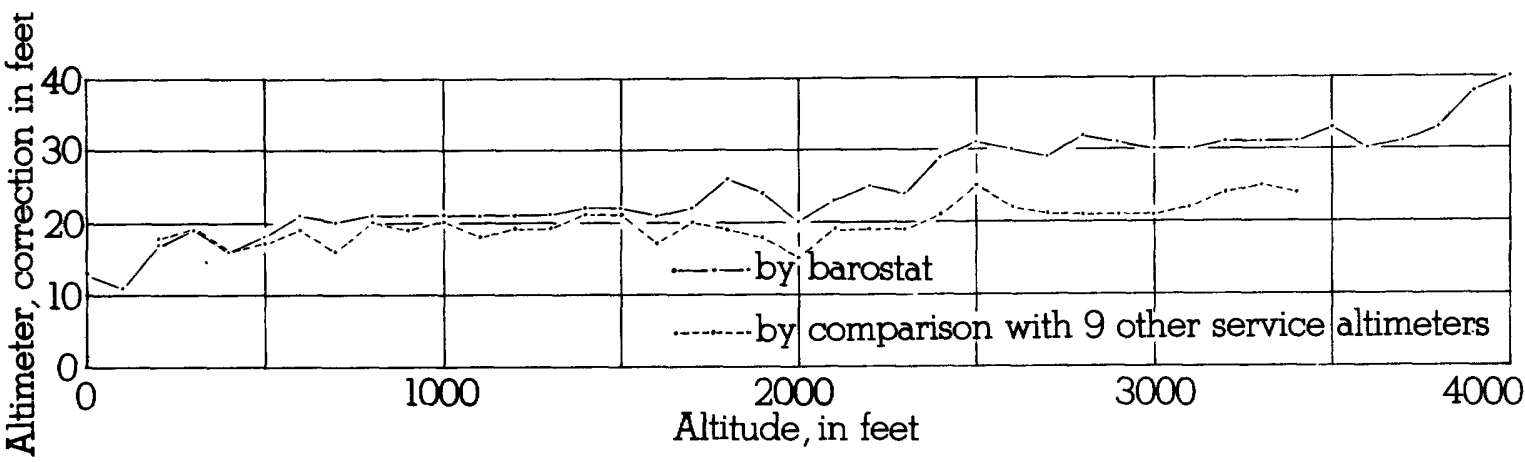

Figure 6. --Calibration curves for service altimeter T-25270.

comparisons. Moreover, field tests in which pairs of altimeters are used at each field station reveal discrepancies of several feet between instruments, after all corrections have been applied. Some of these discrepancies undoubtedly are caused by inadequate calibration.

Although the 6-foot calibration error discovered in the Bull Run test survey was particularly noteworthy, many similar anomalies in calibration curves have been demonstrated by laboratory calibrations. Altimeters with such irregularities require more careful

3

Skilled observers, using laboratory test chambers, can consistently check their readings to 1 foot. Field comparisons can seldom be made with such accuracy; however, simultaneous readings could be obtained by using a camera. calibration, and the corrections determined for them are not dependable because the points of calibration do not necessarily coincide with the points of change of the optimum calibration curves. To obtain the high accuracy required in supplemental control surveys, there is a critical need for altimeters that can be calibrated quickly and accurately and that do not exhibit serious anomalies in their calibration curves.

\section{CHARACTERISTICS OF AN IDEAL SURVEYING ALTIMETER}

In describing an "ideal" surveying altimeter, some compromise must be made between the desirable and the practical. An altimeter accurate to 0.1 foot under all conditions is highly desirable, but practical

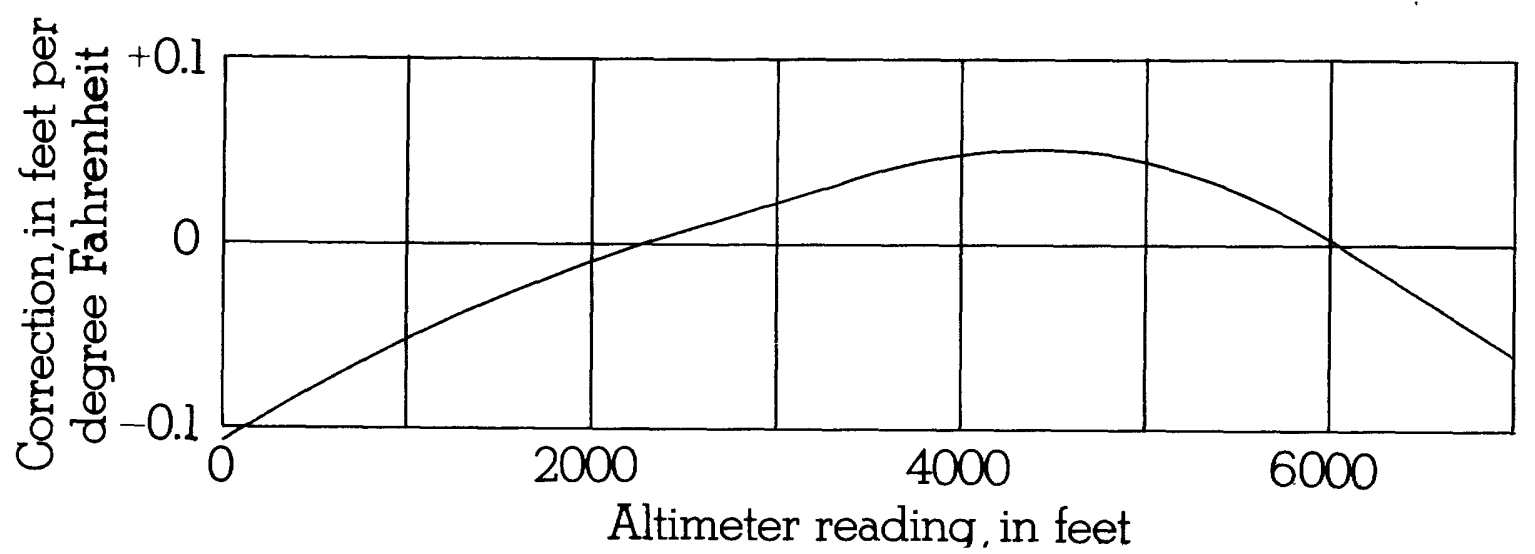

Figure 7.--Temperature correction curve for a service altimeter. Corrections are algebraically additive for temperatures above $75^{\circ} \mathrm{F}$ and subtractive below $75^{\circ} \mathrm{F}$. 
considerations limit the instrument to one of reasonable size and cost, for which instrumental and observational errors combined are small in comparison with atmospheric errors

Net accuracy. --The altimeter should yield elevations correct within 1 foot under all conditions of temperature and pressure, after appropriate corrections have been applied.

Temperature characteristics. --Altimeters are subjected to a constant temperature of $75^{\circ} \mathrm{F}$ while being graduated and therefore require no temperature corrections when used in the field at that temperature. Although the effects of variations from the standard temperature are largely compensated in the design and fabrication of the instrument, the manufacturer supplies a temperature correction curve, similar to figure 7, so that any residual error due to temperature variation can be eliminated. It should be emphasized that this correction is entirely separate from the air-temperature correction factor previously discussed and that it is valid only when the instrument is in thermal equilibrium or the temperature is changing slowly. Instrumental temperature corrections usually are quite small, seldom exceeding 2 feet, a figure which may be taken as an acceptable maximum.

Only two temperature effects are consequential in a well-designed altimeter: dimensional changes in the mechanism and elasticity changes in the pressure-sensitive element. Temperature effects on the gas within the pressure-sensitive element are avoided by evacuating the pressure capsules to less than 0.05 inch of mercury at $75^{\circ} \mathrm{F}$.

When readings are taken on an altimeter that is not in thermal equilibrium, serious errors are likely to result. This can be demonstrated by placing an altimeter in a test chamber at a given pressure and a temperature of $100^{\circ} \mathrm{F}$.

\footnotetext{
${ }^{4}$ Peterson, J. B., and Freeman, J. R., Jr., 1922, Precision altimeter design, in National Advisory Committee for Aeronautics Report 126, Altitude instruments: pt. 2, p. 36 .
}

After an hour, all parts of the altimeter should have reached a uniform temperature, and the altitude reading, corrected for instrumental temperature, will equal the equivalent altitude of the test system. If the temperature is then suddenly dropped to $30^{\circ} \mathrm{F}$ at the same pressure, the pointer of the altimeter will swing away from the original reading for a few minutes, reverse direction, and swing back (some altimeters will go into full oscillation, with gradually decreasing amplitude). After some time, which depends on the time-lag constant of the instrument, the pointer will come to rest, and the corrected altitude reading will again agree with the equivalent altitude of the test system.

For maximum speed in field use, the thermal time-lag constant of the altimeter should be as short as possible. Moreover, temperature changes larger than 5 degrees should be avoided, and the altimeter should be shaded from the direct rays of the sun. If large changes in temperature cannot be avoided, the altimeter must be held at a constant ambient temperature for a suitable time before readings are taken.

Hysteresis. --An altimeter should indicate the same scale readings with pressure increasing or decreasing, regardless of the magnitude or rate of change of pressure. However, a small time lag is inevitable because of the imperfect elastic characteristics of the materials from which the pressure-sensitive element and flexural parts are fabricated. In a perfectly elastic material, strain would be exactly proportional to stress, as stated in Hooke's law; unfortunately, no such material is available.

The absolute accuracy obtainable in an altimeter is thus limited to a large degree by the elastic characteristics of metals. In the pressure-sensitive element, atmospheric pressure is balanced by the elastic forces of the element, and it is essential that the metal follow Hooke's law, within a few millionths of an inch, throughout the pressure range for which the element is designed. (Actually, it is necessary only that the elastic behavior of the metal be consistent and repeatable.) 
If a loading spring is used, its elastic performance must be correspondingly consistent. In general, the elastic error or inconsistency of metals is proportional to about the fifth power of the applied stress. If springs and elastic members are designed so that the applied stress does not exceed about three-tenths of the classified yield-point stress, hysteresis and elastic errors are held within acceptable limits.

Time is an important factor in analyzing elastic errors. If an elastic member is stressed a given amount, the resultant deformation will continue to increase for an indefinitely long period of time, toward a condition of equilibrium, as shown in figure 8 . With the time abscissa plotted on a logarithmic scale, the curves approximate straight lines for a considerable distance but probably do not continue along straight lines indefinitely. Elastic error usually is plotted as a percentage of total strain or deformation, as in figure 8 , the percentage being proportional to about the fourth power of the applied stress. Change in elastic error with temperature is not considered serious within the temperature range to which altimeters are subjected.
In a well-designed altimeter, the materials used and the stresses applied are such that the total elastic error is very small and deformation approaches the equilibrium point, within undetectable limits, in a few minutes. Five minutes after a change of pressure, an altimeter should not show lag exceeding $1 / 2000$ of the pressure change.

Although for small stresses quartz has optimum properties of elastic performance and variation of elastic coefficient with temperature, it is not a practical material for altimeter pressure elements because it is difficult to fabricate and becomes fragile under the stresses required of pressure elements; also, it often fractures under shock or because of scratches on its surface. Materials widely used for pressure elements because of their superior elastic characteristics include beryllium copper, phosphor bronze, and Nispan C; however, they must be carefully heat treated and hardened to obtain the required elastic properties.

${ }^{5}$ Stott, L. L., and Carson, R. W., 1938, Stability of some alloys for springs compared: Metals and Alloys, no. 9, p. 233-36.

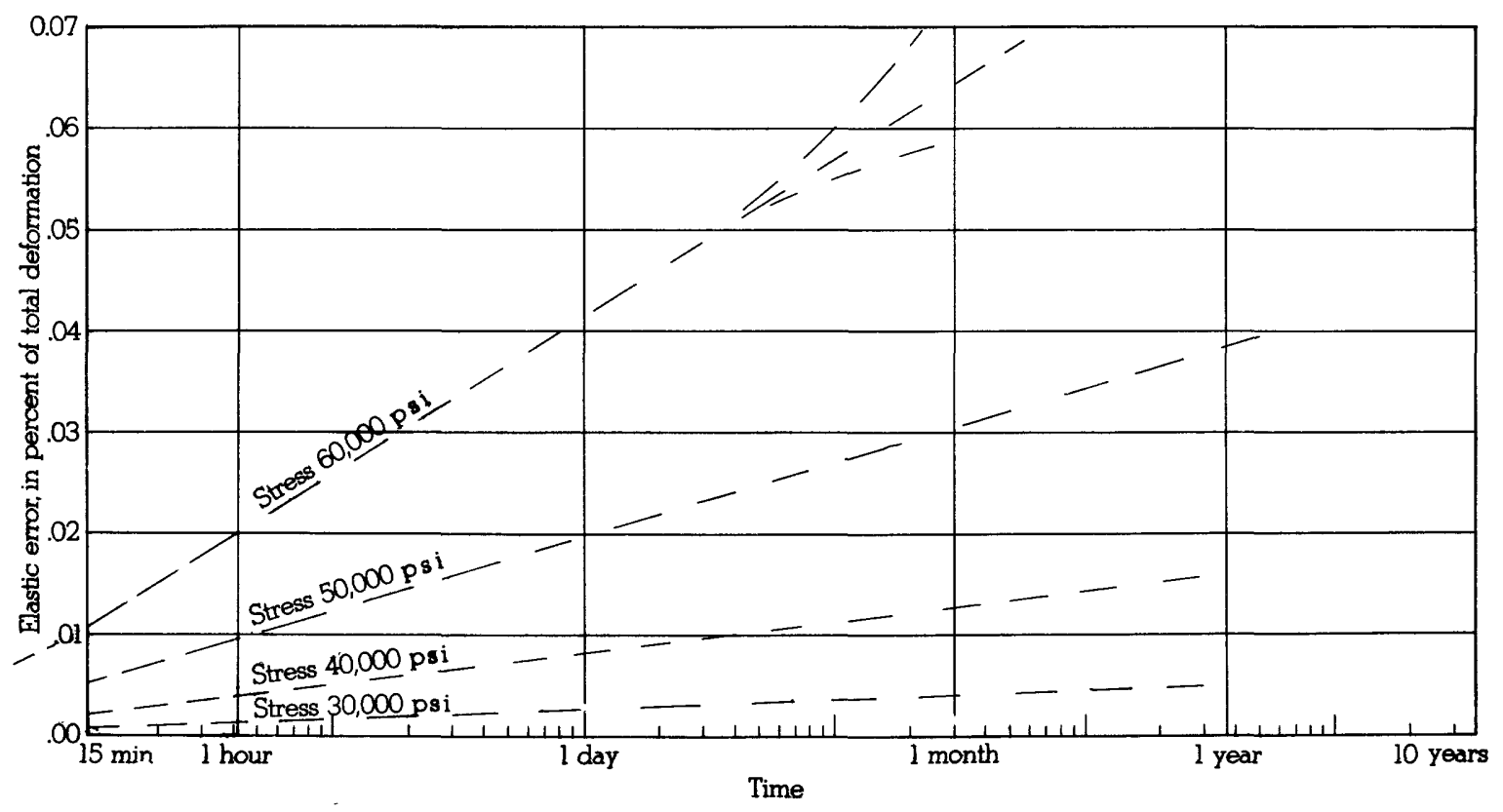

Figure 8.--Generalized graph of change in elastic error with time and stress. 
Rapid response. --The altimeter must respond as rapidly as possible to any change of altitude greater than 0.5 foot, or 0.005 inch of mercury. For use under all field conditions, including helicopter transportation from station to station, it should track a change of altitude to an accuracy within 1 foot at any rate of change up to 1,000 feet a minute.

\section{Controlled pressure equalization. --} Although inadequate circulation of air between the interior of the altimeter case and the external atmosphere can cause excessive lag in response, this effect can be controlled and used to advantage by proper design. In some types of altimeters, the case is airtight except for a capillary tube, permitting the instrument to be sealed for transportation at high altitudes. Such altimeters also can be connected into pressure-calibration systems that do not use vacuum test chambers.

A capillary tube that controls the rate at which the internal air reaches equilibrium with the surrounding atmosphere will largely eliminate the effects of small, rapid fluctuations in air pressure which are caused by local disturbances, such as a car or truck passing by along a highway or a door opening and closing in the office or laboratory. Atmospheric disturbances of this sort are shown in the barograms (App. B, p. 30).

Stability. --Each time an altimeter is subjected to the same test conditions of pressure, temperature, and humidity, it should indicate the same scale reading. Some altimeters, however, exhibit a gradual change, usually constant over the instruments' range, which may amount to several feet a year. The rate of change should not exceed 2 feet a year. An abrupt change or a variation in the rate of change generally means that the altimeter has been intentionally disturbed or adjusted. A gradual increase in altitude readings for a given test pressure may indicate a leak in the pressure element.

Ease of calibration and regularity of curve. --Surveying altimeters usually are calibrated in vacuum test chambers, but instruments with sealed cases and outlet tubes also may be connected into a test system by means of vacuum lines, a procedure which is often used for field comparisons. Null-type altimeters are difficult to calibrate and require special test equipment because they must be adjusted manually before each reading; if these instruments were equipped with sealed cases, calibration would be simplified.

The calibration correction curve for each altimeter should be as nearly linear as possible. The differential between the corrections for adjacent 100-foot graduations should not exceed 1 foot. Altimeters with the physical characteristics previously described in this section could be expected to have nearly linear calibration curves. Moreover, they would be easy to calibrate because only a few points on their scales would have to be compared with the laboratory standard.

Adequate range. --To a considerable extent, the accuracy of an altimeter is inversely proportional to its range because the greater the range the greater the stresses, flexural deformations, and elastic errors. Therefore, wide range and high accuracy are essentially conflicting characteristics in an altimeter. If altimeter surveys on a given project are limited to an elevation range of 2,000 feet, as previously discussed, and a factor of 1,500 feet is allowed for variations in atmospheric conditions, the ideal surveying altimeter would have a range of 3,500 feet. However, setting the range this low for maximum accuracy would require multiple models of the altimeter, each for use within a specific range of elevation. Economic considerations in manufacturing and the overlapping of elevation ranges in field operations will probably make it necessary to increase the range to 5,000 or 7,000 feet.

Size, weight, and ruggedness.--For field use, an altimeter should be convenient to on foot over difficult terrain. With carrying case, it should weigh not more than 5 pounds. The carrying case should be waterproof, wear resistant, shock absorbent, and insulating. 
The altimeter should be rugged enough to withstand the normal jars and shocks of field use. If the case is sealed, it must withstand differential pressures, such as those encountered when the altimeter is tested at low elevations or when it is sealed off at high elevations and then carried to low elevations.

Ease of use. --Although precedures have been developed to guard against blunders in reading, much depends on the ease with which the scales can be read. The scales should be clearly graduated, adequately illuminated, and free of parallax. It should not be necessary to level the altimeter precisely.

Cost. --Although cost is an important consideration, and high cost would restrict the potential market, a surveying altimeter meeting the requirements described above could command a price several times that of present instruments.

\section{CONSIDERATIONS IN ALTIMETER DESIGN}

Pressure-sensitive element

Of the three general types of pressuresensitive elements, the vacuum box (Naudet type) is most widely used in altimeters and is the only one which will be discussed here. The bellows (Sylphon type) is employed in the barostat. The third type is the Bourdon tube.

The vacuum box consists of two corrugated elastic diaphragms joined together at their rims. Because of the needs of aviation for accurate altimeters, much research and development work has been directed toward perfecting the performance of vacuum-box pressure-sensitive elements. Significant results of this research include the following:

Materials with better elactic characteristics and smaller temperature effects, providing greater displacements for given pressure changes. Also, some pressure-sensitive elements have been designed so that the displacement of the element is linear with respect to changes in altitude.

\section{Improved methods of forming the diaphragms.}

Improved methods of heat treatment.

Improved methods of joining the diaphragms to form the vacuum box.

Older designs for pressure-sensitive elements incorporated auxiliary springs to keep the vacuum boxes from collapsing under atmospheric pressures. The springs were either helical or leaf shape and were placed either inside or outside the vacuum box. However, the auxiliary-spring designs are now relatively obsolete, and the surveying altimeters used by the Topographic Division have vacuum boxes that are stiff enough not to require auxiliary springs. Consequently, the pressuresensitive elements are under relatively heavy stress at sea level.

\section{Freedom from constraints}

To minimize elastic errors, the pressure-sensitive element must move without constraints. The displacement-indicating mechanism should be designed so that all its parts are as light in weight and as free of friction as practicable. When two or more vacuum boxes are connected in tandem to increase the magnitude of displacement, some constraint is unavoidable because the weight of one box acts on the other. (Another consideration in tandem mounting is the mechanical instability of the system.) As a result, more than three vacuum boxes are seldom used in tandem.

It is often erroneously assumed that, aside from gravitational forces, the displacement of the vacuum box is affected only by

\footnotetext{
${ }^{6}$ It can be proved that the elastic time effects in an aneroid barometer can be reduced If a spring with good elastic properties is used in conjunction with a relatively very flexible diaphragm, although the diaphragm had large elastic time effects." M. D. Hersey, 1916, Theory of stiffness of elastic systems: Jour. Washington Acad. Sc1., v. 6, p. 569.
} 
unknown, negligible constraints. The elastic performance of the altimeter would be markedly improved if the displacement of the pressuresensitive element were measured without in any way constraining the movement of the element. One theoretically possible solution to the problem would be to use monochromatic light and an interferometer. Such a device, used in conjunction with a good pressure-sensitive element and designed to measure vacuum-box axial displacements as small as 0.000001 inch with negligible error, could provide altitude readings accurate to 0.1 foot. However, as an instrument of this type would hardly be considered practical for field use, other approaches to the problem must be considered.

Electronic methods. --Although practical considerations make it necessary to accept some compromises in design, the use of electronic devices holds some promise of approaching the ideal in measuring displacements ments of the pressure-sensitive element.

One electronic method is to mount one of the electrodes of a capacitor, known as the pressure plate, on the free end of the pressuresensitive element or vacuum box? This electrode is in the form of a lamina or plate, with its two surfaces plane parallel, and must be as light in weight as practicable. The plate is mounted so that its plane surfaces remain perpendicular to the central axis of the vacuum box when the free end of the box and the plate are displaced by pressure changes. The opposite or fixed end of the vacuum box is rigidly attached to the frame or chassis of the altimeter. Also mounted on the frame is a micrometer mechanism which holds and moves the opposing plate (or plates) of the capacitor, called the measuring electrode. The measuring plate and micrometer system are alined to keep the surfaces of the measuring plate parallel and in close proximity to those of the pressure plate. The micrometer is used to measure displacements of its electrode from a standard position relative to the pressure electrode.

"The term "vacuum box" is employed when the box itself is considered, without accessory mechanisms, linkages, or springs. The term "pressure-sensitive element" denotes the entire unit, with accessories.
The pressure and measuring electrodes constitute a variable capacitor, which is connected into an electronic micrometer circuit, usually a bridge circuit. By suitable displacement of the measuring plate, the capacitance is adjusted and the associated circuit brought to a standard condition (either maximum or zero current, as read on a meter). The electrostatic force exerted on the pressure plate by the measuring plate can be reduced to a negligible amount through careful design of the electronic circuit. The system therefore approaches the ideal of a free-movement vacuum box and is free of errors due to friction, linkages, and springs.

In an alternative electronic method, movement of the vacuum box could be measured by means of the variations of inductance between two coupled coils.

Both the electronic methods described here require either manual or servomechanical adjustments fo obtain altitude readings. This might not be a disqualifying objection for field use, but calipration procedures would be difficult.

Designs employing micrometers and electrical contacts to measure vacuum-box displacement have proved unsatisfactory because of variations in the pressure needed to make contact. Errors also result from variations in resistance due to corrosion of the contact points.

Null methods. --One well-established means of reducing elastic errors is to apply the null principle, in which stops restrict the center connections of the vacuum box from moving more than a few thousandths of an inch under any pressure conditions. In field instruments of the null type, spring tension is applied to the box; for each altitude measurement the tension is adjusted to bring the sensing end of the vacuum box to the null position between the stops, by centering the null-indicating needle over its index mark. The altitude reading is obtained by means of a micrometer system, which measured the amount the equalizing spring has been extended to bring the vacuum box to the null point. Although the vacuum-box 
connections do not move apprec on the diaphragms changes con: extreme variations in atmosphe as can be seen in figure 9 . The viously described, can be consi ment of the null type in which tr measurements are based on weiynts ralnter than spring movement.

\section{Performance requirements}

An average vacuum box is displaced 0.1 inch by a 10,000-foot difference in altitude. If 0.1 -foot sensitivity and 0.5-foot accuracy are sought, the measuring system must be sensitive to 0.000001 inch and accurate to 0.000005 inch. These extreme degrees of response have been attained in electronic altimeters (note agreement between the barograms in Appendix $B$ ), and there is good evidence that the best vacuum boxes will respond with comparable accuracy in field instruments.

In a surveying altimeter of the indexing type, the multiplying mechanism causes the needle to traverse about 40 inches of scale for the 0.1 -inch displacement of the vacuum box, thus providing a multiplication factor of 400 . Two different methods of improving the performance of pressure elements have been outlined. In one method the pressure-sensitive element is allowed the freest possible movement; in the null method, movement is restricted to a very small amount. Although either

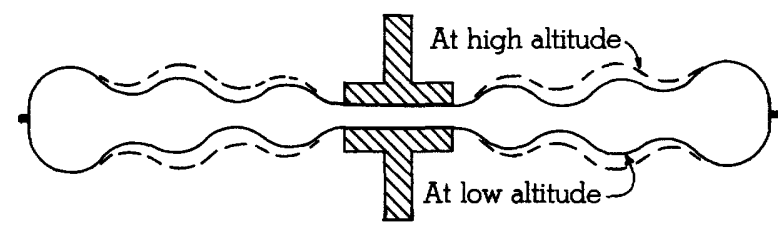

Figure 9.--Cross-sectional diagram of vacuum box in null-type altimeter, showing elastic movement of diaphragms (exaggerated) under extreme of pressure when center connections are restricted by stops.

method may bring the performance of pressure elements within the standards sought, the micrometer and other measuring mechanisms thus far investigated (weight systems excepted) seldom have performed with the desired accuracy. Therefore, it has been concluded that an optical magnification system will provide the most practicable approach to the ideal surveying altimeter.

\section{THE OPTICAL ALTIMETER}

Optical magnification

The use of optical, rather than mechanical, magnification offers many advantages, the most significant being a great reduction in the number of mechanical parts, so that the design approaches the ideal of free movement, in which nothing touches the free end of the vacuum box in the course of the measurements. Figure 10

\section{Focus adjustment}

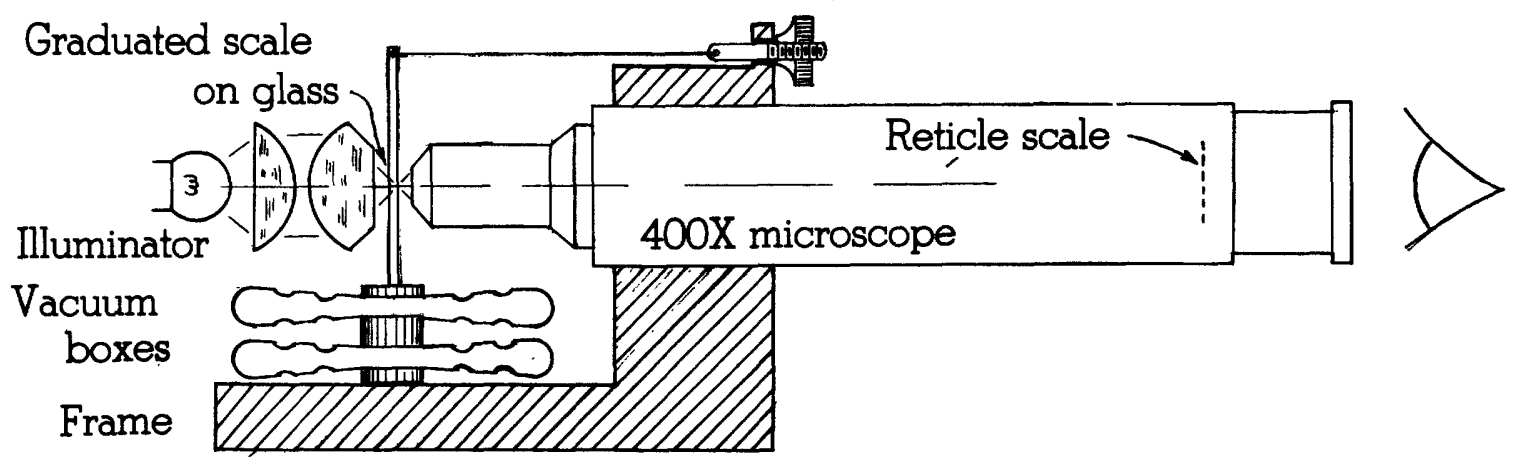

Figure 10. --Schematic diagram of direct-reading optical altimeter. 
illustrates a design of this type, in which a scale attached directly to the free end of the vacuum box is viewed through a microscope. However, to provide $400 \mathrm{X}$ magnification, a relatively high-powered microscope, with its minute depth of field, and an adequate system of illumination are needed. If built to laboratory standards, the microscope would require an $8-\mathrm{mm}$ objective and a $20 \mathrm{X}$ eyepiece and would have a depth of field of about 0.000002 inch.

The possibilities of this basic design have not yet been exploited. It would not be necessary to follow the strictest laboratory standards in building the reading microscope. Nevertheless, the requirements for depth of field, illumination, and other factors indicate that a completely free-moving pressure-sensitive element could not be used because a very slight lateral restraint would be needed to maintain or adjust the focus.

A modification of the free-movement optical-reading design has been explored to a limited extent. (See fig. 11.) This modified design employs a small tilting mirror, linked to the moving end of the vacuum box, which reflects the image of a finely divided glass scale into a $50 \mathrm{X}$ reading microscope. Although artificial illumination would not usually be necessary, the size of the mirror (a problem requiring careful consideration) could be reduced if artificial illumination is used. Moreover, the altimeter could then be used regardless of natural lighting conditions. To avoid adverse effects on the pressure-sensitive element, all the heat produced by an illuminating lamp, except that of the pencil of light passing through the glass scale, could be kept outside the instrument case.

${ }^{8}$ This lateral restraint could be negligible. It is assumed that the scale would have 100-foot divisions, that the microscope would have $a$ reticle with 5-foot or smaller divisions, and that the scale would be adjusted laterally into focus instead of moving the microscope.

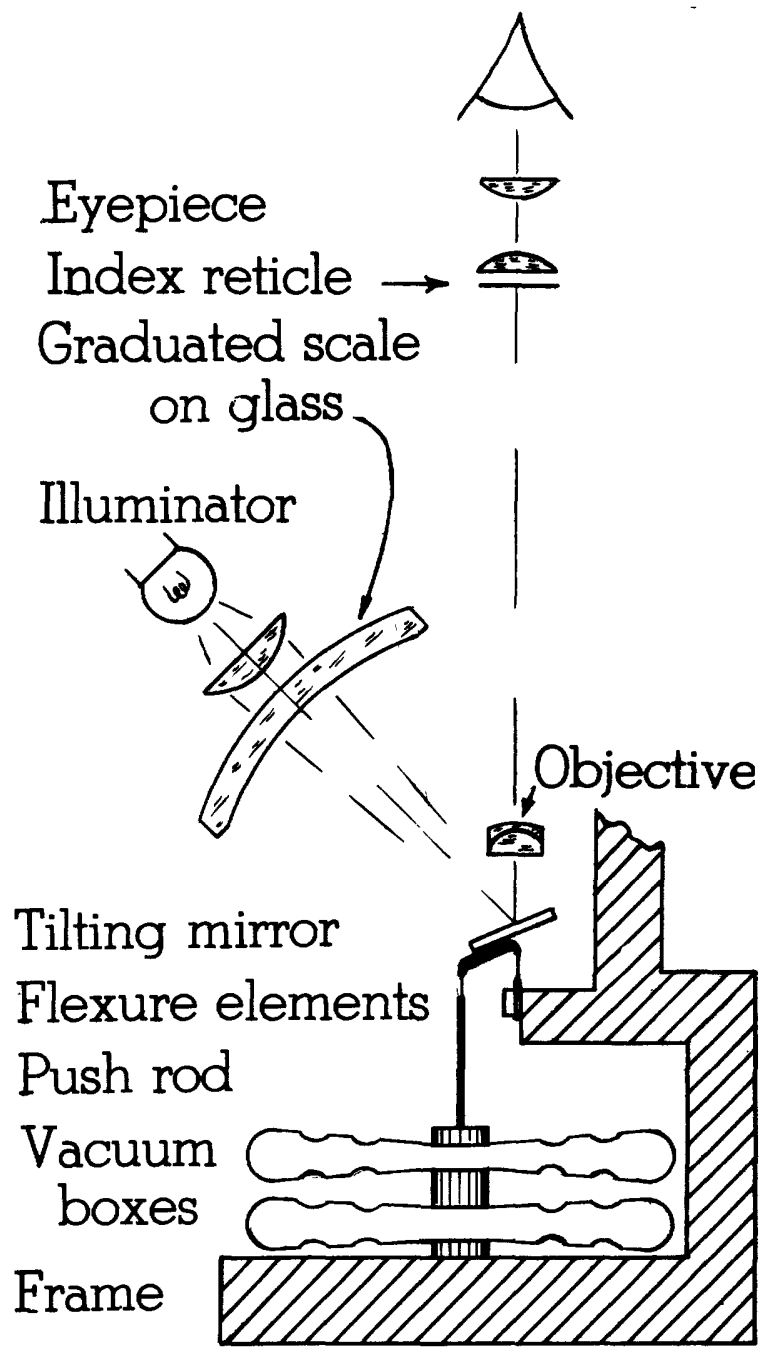

Figure 11. --Schematic diagram of tiltingmirror optical altimeter. Flexural elements shown below proper position for clarity.

Experimental optical altimeters

Two of the three experimental altimeters, models X-1 and X-2, thus far constructed by the Geological Survey are illustrated in figures 12 through 15. Although these prototypes have not been temperature compensated and are not ready for field use, their performance in the laboratory indicates excellent 


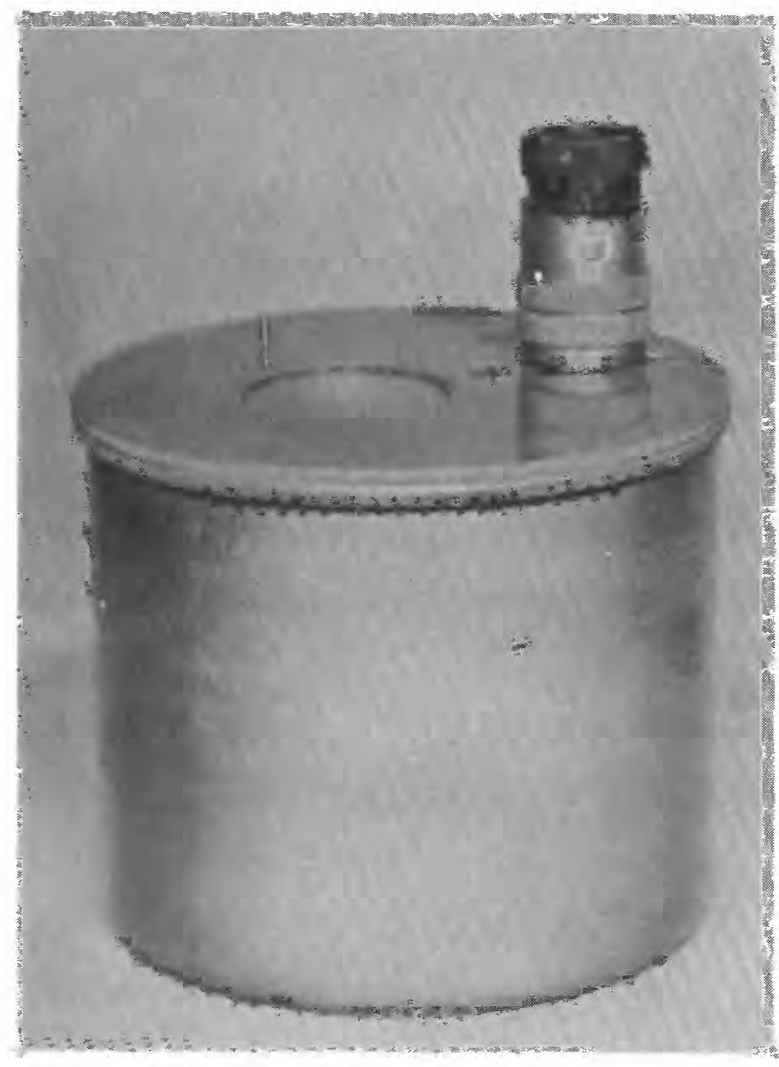

Figure 12.--Experimental optical altimeter, model X-2.

possibilities. A further indication is that only a minor part, rather than the major part, of instrumental error in commercial altimeters is caused by the vacuum box. A brief discussion of the principal parts of model X-2 follows.

Microscope. --The reading system consists of a $32-\mathrm{mm}$, f:4 achromatic objective, a pentaprism to bend the light rays $90^{\circ}$, a glass reticle with a single index line, and a well-corrected $25 \mathrm{X}$ eyepiece. As the objective is $2.4 \mathrm{X}$, total magnification is about $60 \mathrm{X}$. Model $\mathrm{X}-1$ is generally similar but has no pentaprism, its design being more nearly as shown in figure 11 . Model X-3 (not illustrated) differs only in minor details from model $X-2$.

For best resolution the objective should be designed specifically for this application, but stock achromats usually will give a fair degree of resolution. Adequate resolution probably

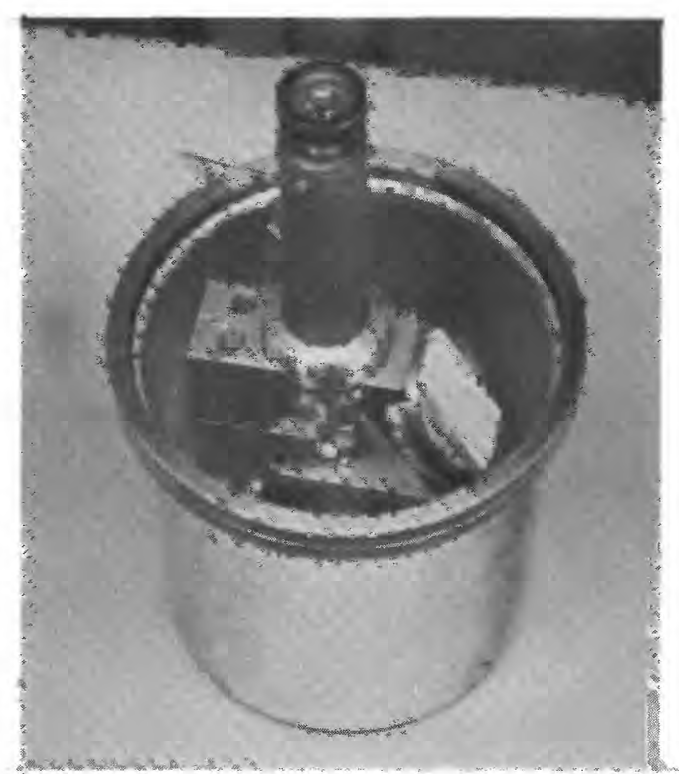

Figure 13. --Experimental optical altimeter, model X-1, showing internal construction through structural plastic top which supports altimeter.

could be obtained with an aperture of $6 \mathrm{~mm}$. This would permit the use of a smaller, lighter mirror and also would increase the depth of focus. Maintaining focus over the entire scale range has not been a serious problem in the prototype altimeters, but it must be carefully considered in future designs.

\section{Mirror. --It is highly desirable that} the mirror be as small and light as practicable because flexure-element stiffness and the resulting load on the vacuum box are approximately proportional to the size of the mirror.

Decreasing the size of the mirror will improve ruggedness and reduce sensitivity to tilt. The $1 \times 8 \times 12 \mathrm{~mm}$ first-surface mirrors used in the prototype models probably can be reduced in size in future models, with beneficial results. The mirror must, of course, be large enough to reflect the light rays from the graduations to the objective lens and must be sufficiently flat to have no degrading effect on image quality. The mirror supports in the experimental models were fabricated from solid aluminum alloy, and the mirrors were attached to the supports with an adhesive. 
INSTRUMENTAL IMPROVEMENTS IN ALTIMETRY

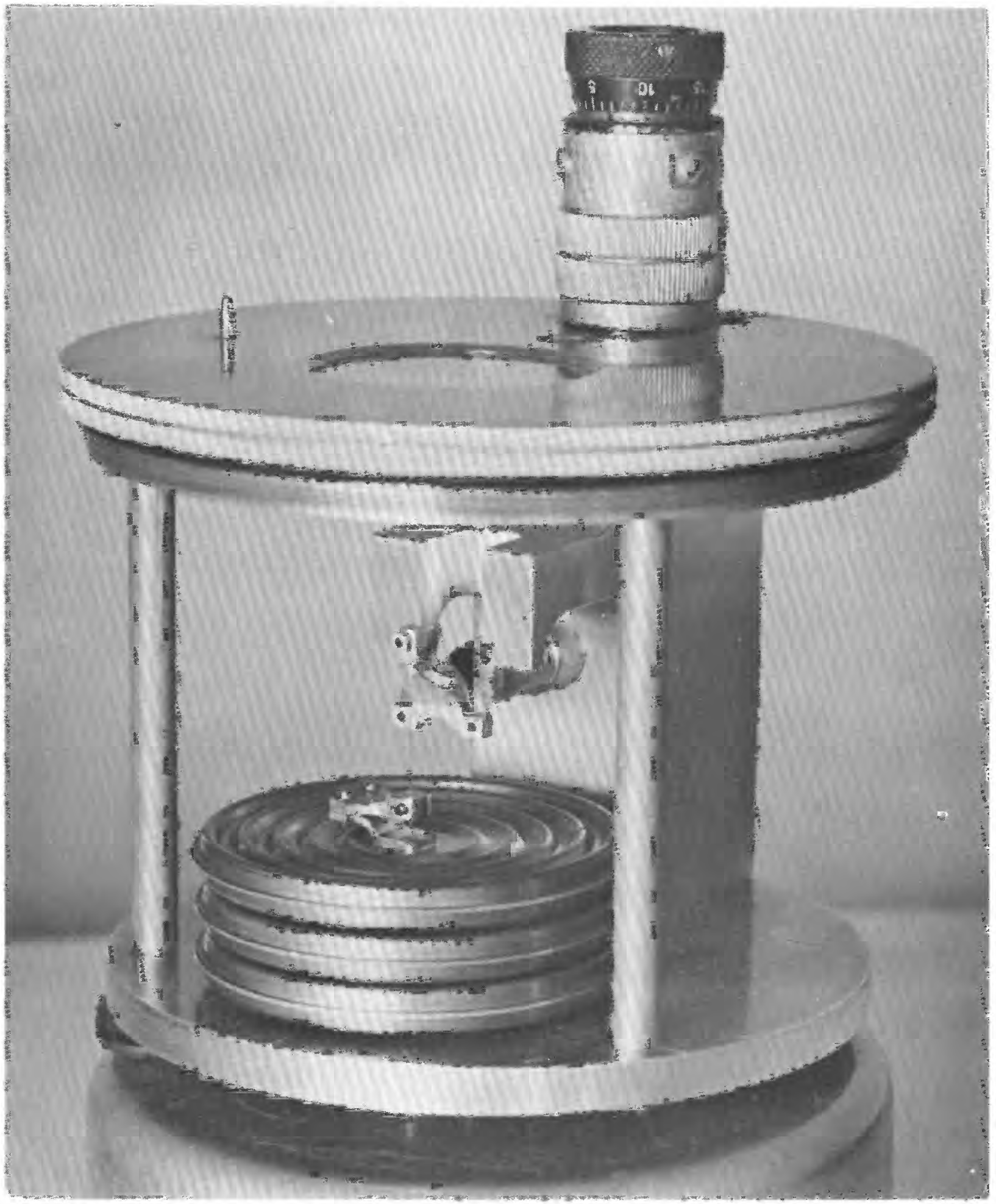

Figure 14. --View of model X-2 with case removed, looking toward objective. 


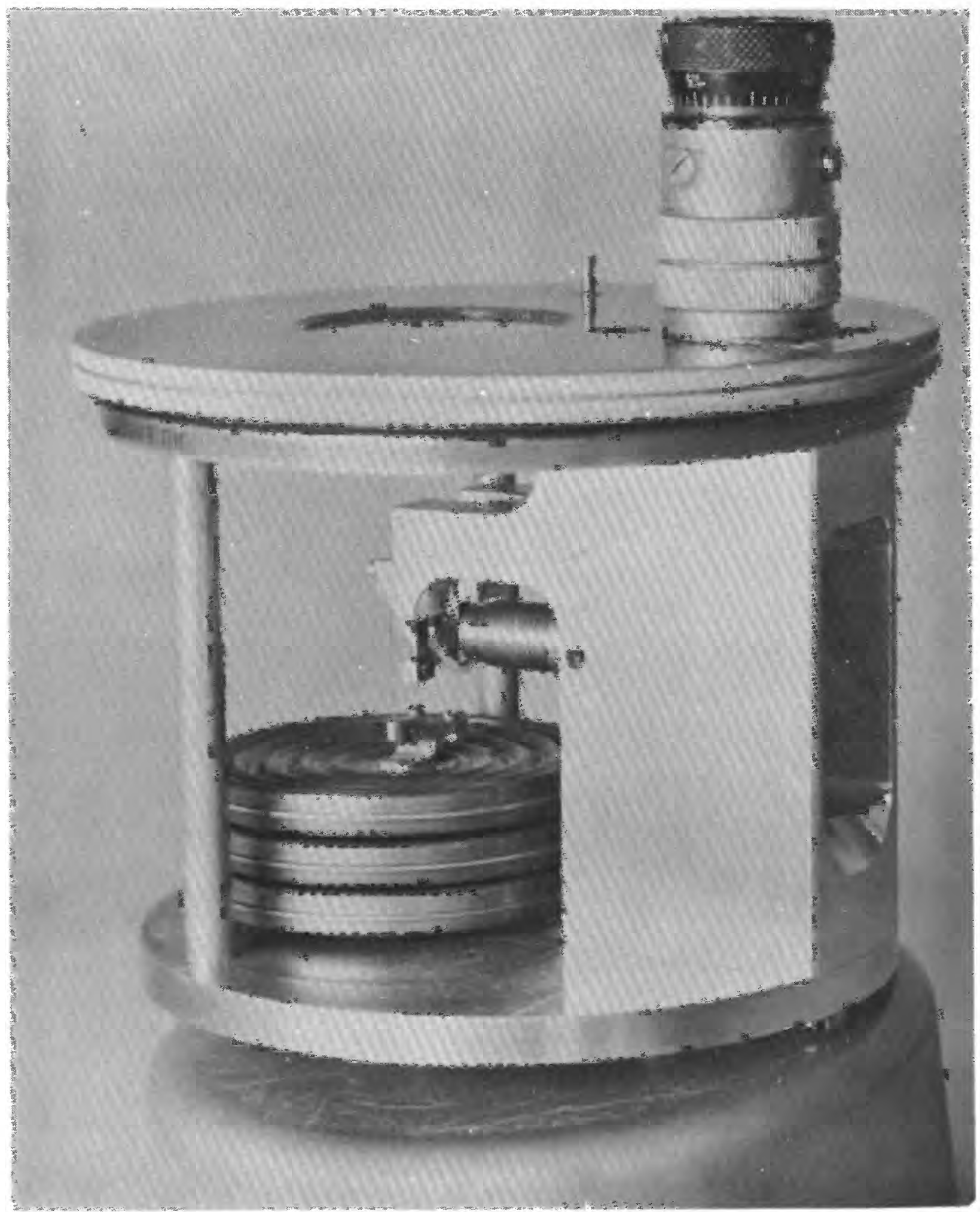

Figure 15. --View of model X-2 with case removed, looking toward mirror. 
Graduated scale. --A tilting mirror microscopic reading system requires graduations on a cylindrical or spherical surface whose center of curvature lies on the mirror's axis of rotation. Although it is more difficult to produce graduations on a curved surface than on a flat one, the problem is not serious. In the experimental altimeters, spherical glass elements of ophthalmic quality and with concentric surfaces were used, rather than cylindrical elements, because the spherical elements were readily available and easy to mount. Graduations were photographically processed onto the glass blanks by contact printing from a $20 \mathrm{X}$ reduction of a millimeter scale. The scales are about $30 \mathrm{~mm}$ long and contain 20 lines per $\mathrm{mm}$; line width is about 10 microns. As each graduation represents 10 feet, total range is 6,000 feet; the operating range is about 5,000 feet.

Scales with as many as 40 lines per mm and line widths as small as 3 microns are available commercially. These limits seem adequate for the present; but, should the need arise, laboratory microscope stage scales with 100 lines per $\mathrm{mm}$ and a line width of 1.5 or 2 microns can be obtained. For altimeters with a 5,000-foot range, limitations of magnification, mirror rotation, and focus will also limit the length of the scale and probably will not permit graduations at intervals of less than 5 feet. Even though a unit-foot scale could be included in the reticle, it is doubtful that such a reticle is superior to a single index line and interpolation between 5 - or 10-foot graduations. Tests with other optical instruments have shown that the average individual can, without special training, interpolate to tenths of intervals with errors averaging 1/20 interval.

Field readings should be taken in sets of three or more. One accepted procedure is to take three readings at each field station, at timed intervals of 1 or 2 minutes, and use the mean of the readings. This procedure reduces errors of interpolation and errors due to local disturbances and provides a check against blunders. If such a reading procedure is followed, interpolation to unit feet between 5 or 10-foot graduations is considered adequate.
Flexural elements.--As it is believed that a serious amount of instrumental error is caused by improper design of the flexural elements and the use of solder to hold them, the flexural supports for the mirrors in the experimental altimeters were fastened to milled surfaces with 1/8-inch square washer-type pads and No. 2 machine screws. The supports are of beryllium copper, $0.004 \times 0.125 \times 0.5$ inch, with a flexural length of 0.25 inch. The mirror rotates a maximum of $11^{\circ}$ from the unstressed position, producing maximum stresses of about 28,000 psi (pounds per square inch). It was assumed that the axis of rotation is situated at the center of the flexural section, and the lack of any serious focusing problems indicates that the assumption is justified though not theoretically exact.

Tilt of the instrument, weight of the mirror unit, and forces exerted by the push rod all tend to shift the axis of rotation from an exact position. Further stabilization of the axis, by adding two similar flexural strips outside and at right angles to the strips actually used, was considered, but tests have not shown this refinement to be necessary. Although other types of pivots, such as jeweled pivots, could be used, flexural pivots are considered decidedly preferable because they do not involve lost motion or sliding friction. It may be practicable to fabricate the mirror support and its flexural elements from a single strip of beryllium copper.

\section{Connecting element. --The connecting} element links the vacuum box to a lever arm on the mirror support. Partial and perhaps adequate temperature compensation can be obtained by using suitable material and dimensions for the connecting element. The length of the lever arm on the mirror support is inversely proportional to the value of a graduation interval (in feet of altitude). Provision is needed for adjusting this value so that variations in pressuresensitive elements can be compensated; an alternative possibility is to vary the width of the flexural strips. The elements used in the experimental models reduce the vacuum-box displacement about 5 percent; an increase in this percentwould be justified as a means of adjusting the vacuum-box displacement. 


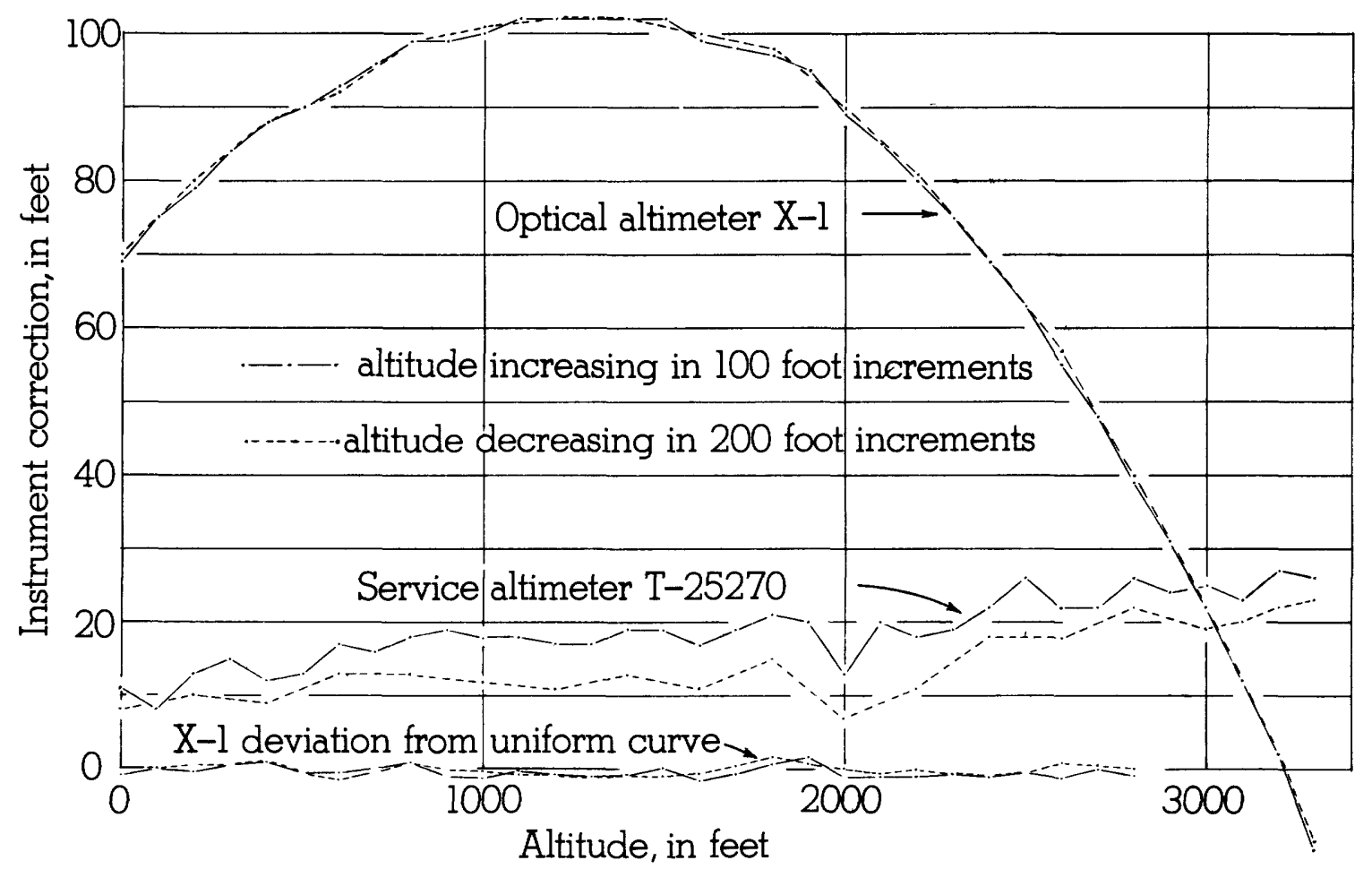

Figure 16. --Calibration correction curves for optical altimeter X-1 and service altimeter T-2527C.

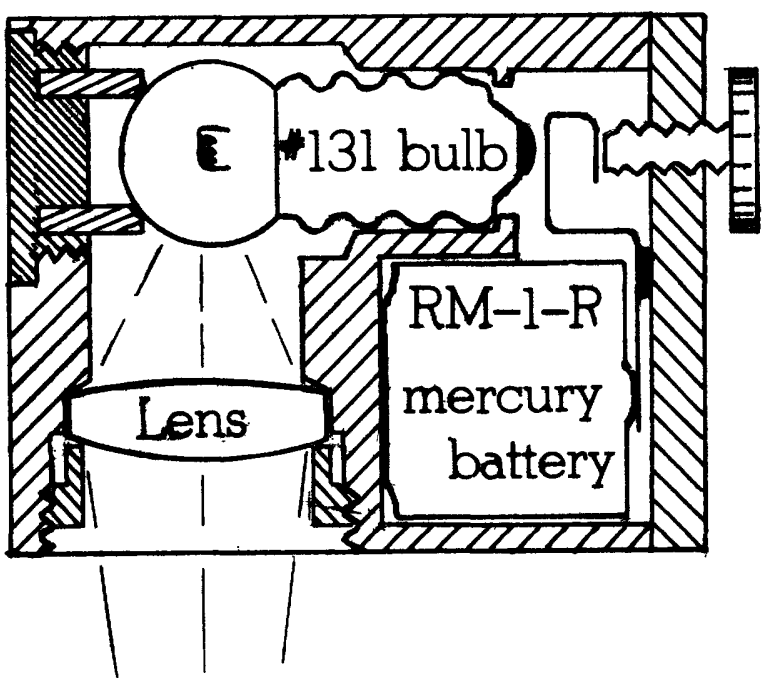

Figure 17. --Cross-sectional diagram of lighting unit for tilting-mirror optical altimeter.
The calibration curve of model $\mathrm{X}-1$ is parabolic in shape (fig. 16). The curve could be made to approximate a straight line by raising the effective pivot point between the connecting element and the lower arm. In the experimental altimeters the connecting arm was constructed of stainless steel wire for convenience, but a material such as an aluminum alloy should be used to provide temperature compensation.

Lighting unit. --After the prototype models were constructed, it was found that the high power of the reading microscope plus the rather small objective aperture made artificial illumination highly desirable in laboratory use. Auxiliary lighting units would be needed for field use under adverse lighting conditions. Moreover, the use of artificial illumination exclusively will permit greater freedom in designing optical altimeters. The lighting unit constructed for use 
with the prototype altimeters provides adequate light together with long battery life. (See fig. 17.) The lamp is held over the part of the scale to be read, and the light is directed toward the mirror.

An important consideration in designing future optical altimeters is adaptability for use in automatic photorecording instruments of the Alticorder type. This use will require a lighting unit that covers a wide portion of the scale or an automatic device for positioning the illuminator.

Frame.--Noparticular effort was made to provide lightweight frames for the prototype altimeters, except to construct the frames from an aluminum alloy. The relatively massive frames do not add an excessive amount to the weight of the instruments. Moreover, they improve ruggedness, deform very little under variable temperatures, and conduct heat quickly to bring the instruments to thermal equilibrium. The complete altimeters weigh 2 pounds each.

Case. - The altimeter case consists of a commercial deep-drawn aluminum cup, modified to permit the top piece to screw into the flange of the cup. The top piece serves both as a part of the framework and as an airtight top for the case. This combination forms a strong protective case but gives no protection against shock. The joint is sealed with an $O$ ring to make the case airtight. For ease of reading, the microscope should extend several inches above the top of the case, but this complicates the problem of providing adequate shock protection. Shock protection can be provided by a sponge-rubber cover that extends up over the top rim, plus a padded canvas carrying case that will also protect the microscope.

The vent tube, which extends half an inch above the top of the case, allows the altimeter to be connected into testing and calibrating systems with plastic tubing.

Vacuum boxes. --The experimental altimeters employ pairs of vacuum boxes in tandem. No adverse effects due to the tandem mounting have been observed. Although pressure elements in which displacement is proportional to altitude rather than pressure are preferred for use in altimeters, the relative merits of the two types of elements have not yet been carefully studied.

\section{Performance of experimental models}

Even though the experimental optical altimeters are not temperature compensated, and no attempt was made to obtain linear calibration curves, their performance in the laboratory has been unusual in regularity of calibration surves, repeatability of results, and freedom from hysteresis. The calibration curve for altimeter X-1 is shown in figure 16 . Although the magnitude of the correction exceeds 100 feet at some points along the curve, the curve itself exhibits a regularity not hitherto observed in the calibration curves of surveying altimeters. Deviations from a uniform parabolic curve are shown at the lower edge of figure 16; at a few points, these deviations are as great as 2 feet per 100 -foot difference in altitude. A significant part, perhaps half, of the deviation may be charged to reading error because the scale graduations in this instrument are quite crude.

The almost total lack of hysteresis, as indicated by the difference between the up and down curves, suggests that perhaps altim eter $X-1$, the barostat (with which the altimeters were tested), and the change-of-pressure indicator (with which the barostat was monitored) may have small and approximately equal amounts of hysteresis. In undergoing a large difference in pressure, the corrugations of the bellows element of the barostat are subjected to strains corresponding to those illustrated for a vacuum box in figure 9 . In a recent modification of the barostat system, the change-of-pressure indicator was fitted with a three-way valve so that it can be left at atmospheric pressure when the barostat is used at high-altitude pressures, thereby providing an accurate check on hysteresis when the barostat is returned to zero-altitude pressure. 
The duration of the calibration plotted in figure 16 was about 3 hours. The two altimeters were held at the pressure equivalent to 3,500 feet of altitude for 15 minutes before the series of decreasing-altitude readings was begun.

\section{Conclusion}

It is hoped that this discussion will lead to a better understanding of the accuracy and possibilities of altimeters and altimetry in general. The laboratory performance of experimental optical altimeters holds considerable promise that the optical design is a practical approach to the ideal surveying altimeter. However, further engineering research and development work is needed to adapt the prototype designs to practical field instruments. It is hoped that this work will be undertaken by commercial instrument manufacturers. 


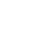




\section{THE AIR DENSITY CORRECTION FACTOR IN ALTIMETRY}

The two-base method of altimetry does not take into account the change in air density due to the variation of air temperature with altitude. To provide a check on air density, air temperatures usually are recorded at all base stations although the two-base formula does not require this information. If the difference in elevation between the high and low bases exceeds 500 to 1,000 feet, the variation of air temperature with altitude should be taken into account. The following article, written by us in 1955, explains a method for doing so.

The determination of altitudes from altimeter readings in mountainous areas is less accurate than in areas of low relief for several reasons. Probably the main reason is that the two-base formula as presently used does not take into full account the variation in pressure of the air column between the low and high bases, there being no consideration of the variation in density due to the decrease in temperature with increase in altitude. The error from this cause is of the order of 1 foot for a difference in elevation between high and low bases of 500 feet to as much as 15 feet for base altitude differences of 2,000 feet.

Corrections must be made for the deviation in air density from $50^{\circ} \mathrm{F}$ and zero percent relative humidity, the conditions assumed in Smithsonian Meteorological table 51, to which W \& $\mathrm{T}$ altimeters are calibrated. In the single-base and traveling-base altimetry methods these corrections are applied directly to the observed altitude differences between two stations as obtained from the altimeter readings at each of these stations. These two corrections are often combined in correction tables or by nomograms. The factor desired is known as Air Temperature and Relative Humidity Correction Factor for Altitude (fig. 1, p. 2). In the following discussion this factor is designated as the air density correction factor.

The air temperature is the most important factor to be used in the evaluation of the air density correction factor. In the field the determination of air temperature is often a difficult matter. For this reason an investigation has been made to determine the comparative accuracy of the air density correction factor computed from only the altimeter readings. This is done in the two-base method and produces satisfactory results for elevation differences less than 500 feet. For elevation differences greater than 500 feet the variation of the air density with elevation becomes important because the air is compressible and air temperature varies with elevation, a variable not considered in the two-base formula.

Only the average air density correction factor for the air column can be determined from two altimeter readings made at locations that differ in elevation. The greater the elevation differences between the two stations, the less the effect of the altimeter observational and instrumental errors. Therefore, the accuracy of the determination of the average air density factor is increased with the increase of the vertical separation of the stations. However, because of the variation of air density with altitude, the greater the difference in elevation, the greater the possible departure of the actual air density correction factor at a given elevation from the average air density correction factor as determined from the altimeter readings.

The average variation of the air density with altitude can be determined for the present purpose from tables used to compute the performance of aircraft and missiles. Several available tables give the values of the air density at different elevations. The table of air density factors prepared from values of air density at different elevations in a manual of the International Civil Aviation Organization, gives the ratio of the density at the elevation designated in the table to the density under standard conditions at sea level.

\footnotetext{
${ }^{1}$ See also Kissam, Philip, 1944, Precision altimetry: Photogram. Eng., v. 10, no. 1, p. $25-43$.

${ }^{2}$ National Advisory Committee for Aeronautics, 1954, Manual of the ICAO Standard Atmosphere: Tech. Note 3182, $132 \mathrm{p}$.
} 
The average air density correction factor is the same as that employed in the two-base method and computed as (7) on the U. S. Geological Survey computation form "Altimeter Elevations" as follows:

$$
(7)=\begin{aligned}
& \text { Average air density } \\
& \text { correction factor }
\end{aligned}=\frac{\text { known difference in elevation }}{\text { difference in altimeter readings }}
$$

The adjustment factor may be determined from three altimeter readings; those at the upper base, the lower base, and at the requested point.

$$
\text { If } \begin{aligned}
\rho_{V_{B}} & \equiv \text { Density factor at the upper base } \\
\rho_{L S} & \equiv \text { Density factor at the lower base } \\
\rho_{R P} & \equiv \text { Density factor at the requested point }
\end{aligned}
$$

the adjustment factor may be computed by the following formula:

$$
\mathrm{K}_{P} \equiv \text { Adjustment factor }=\frac{\frac{\frac{\rho_{L_{B}}+\rho_{R P}}{2}}{\frac{\rho_{L_{B}}+P_{U_{B}}}{2}}}{2}
$$

If we now represent by

$$
(7)^{\prime} \equiv \text { Actual air density factor }=\mathrm{K}_{\rho}(7)
$$

An example will illustrate the computation and application of $(7)^{\prime}$.

The following are values used for an altitude computation by the two-base method on the form, "Altimeter Elevations."

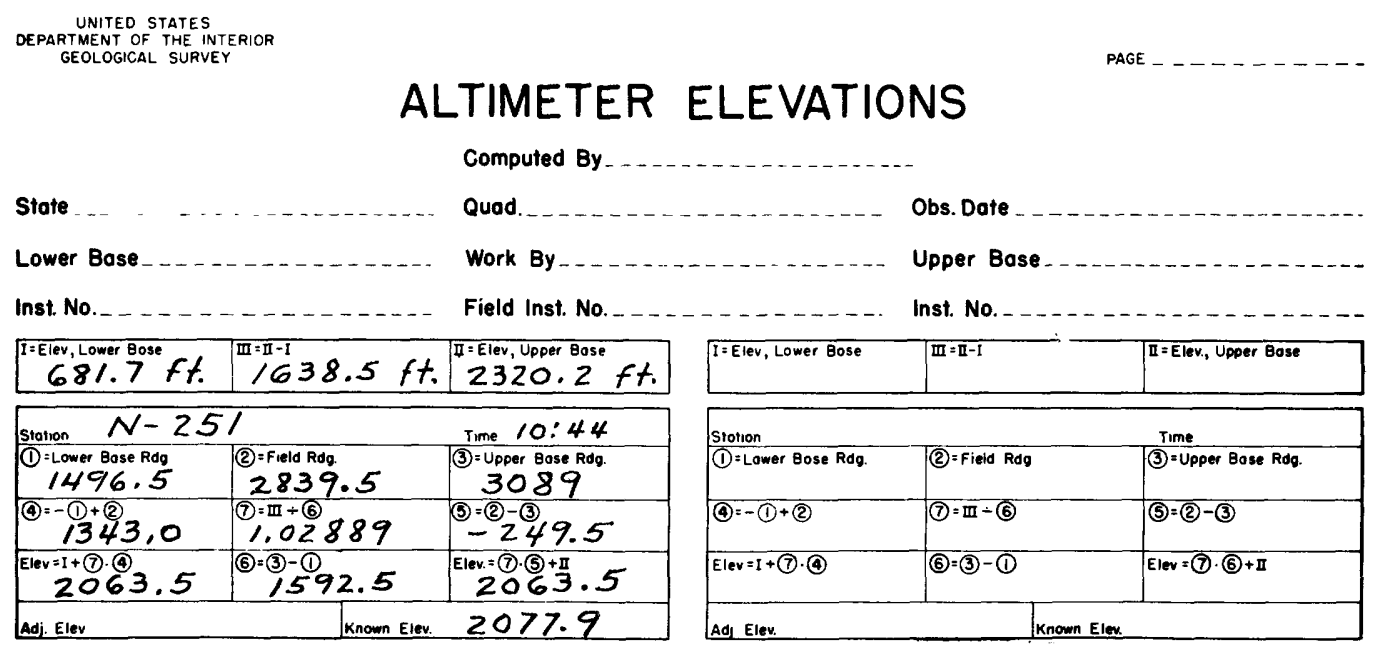


The adjustment factor $\mathrm{K}_{\rho}$ can be determined by a number of procedures from the altimeter readings at the upper base, lowerbase, and the requested point or field reading. One method is as follows:

\section{Numerical Computation of $\mathrm{K}_{\mathrm{p}}$}

By entering the table (p. 26) with these values we obtain

$\begin{array}{llll}\text { Upper base reading } & 3089.0 & & \rho_{\text {us }} \text { from table }=0.9403 \\ \text { Lower base reading } & 1496.5 & \rho_{\text {L }} \ldots \text { do } \ldots=.9855 \\ \text { Requested point } & 2839.5 & \rho_{R P} \ldots \text { do } \ldots=.9472\end{array}$

For computation from lower base

$$
\begin{aligned}
& \mathrm{K}_{\rho}=\frac{\frac{\rho_{Q B}+\rho_{R P}}{2}}{\frac{\rho_{L B}+\rho_{U B}}{2}}=\frac{\rho_{L B}+\rho_{A P}}{\rho_{L B}+\rho_{V B}}=\frac{0.9855+0.9472}{0.9855+0.9403}=1.0035 \\
& (7)^{\prime}=\mathrm{K}_{\rho}(7)=1.0035 \times 1.0289=1.0325 \\
& \text { Elev }=\mathrm{I}+(7)^{\prime}(4)=681.7+1343 \times 1.0325=2068.4
\end{aligned}
$$

The same result will be obtained and the computation checked if the correction factor is computed from the upper base as follows:

$$
\begin{aligned}
& \mathrm{K}_{\rho}=\frac{\rho_{u s}+\rho_{R P}}{\rho_{L s}+\rho_{u s}}=\frac{0.9403+0.9472}{0.9855+0.9403}=0.9802 \\
& (7)^{\prime}=\mathrm{K}_{p}(7)=0.9802 \times 1.0289=1.0085 \\
& \text { Elev }=\mathrm{II}-(7)^{\prime}(5)=2320.2-249.5 \times \mathrm{L} .0085=2068.6
\end{aligned}
$$

A comparison of the elevation value for N-251 as computed by form "Altimeter Elevations" with the above results is presented as follows:

$\begin{array}{ccc}\begin{array}{l}\text { Known elev } \\ \text { of } N-251\end{array} & \begin{array}{c}\text { Elev by } \\ \text { form }\end{array} & \begin{array}{c}\text { Elev using } \\ \text { factor }\left(\mathrm{K}_{\rho}\right)\end{array} \\ 2077.9 & 2063.5 & 2068.5 \\ \text { Error } & -14.4 & -9.4\end{array}$

The evaluation of the actual air density factor (7)' for application to two-base method computations may be accomplished by the employment of the accompanying graph, figure $18^{3}$. The ordinates of this graph represent the value of $b=\left(K_{,}-1\right)$. The abscissas are the values of $(4)$ of form, "Altimeter Elevations." The values of (6) are represented by the diagonal straight lines on the graph.

\footnotetext{
${ }^{3}$ The main purpose of the graph is to avoid the multiplication operation of $K_{p} x(7)$. As the values of (7) and $K_{p}$ are always within a few percent of unity, we can make use of the well-known approximation $(1+a)(1+b)=1+a+b$ when both $a$ and $b$ are small compared with unity.
} 
AIR DENSITY FACTORS

\begin{tabular}{|c|c|c|c|c|c|}
\hline $\begin{array}{c}\text { Mean } \\
\text { Altimeter } \\
\text { Reading }\end{array}$ & 0 & 20 & 40 & 60 & 80 \\
\hline $\begin{array}{r}0 \\
100 \\
200 \\
300 \\
400\end{array}$ & $\begin{array}{l}1.0296 \\
1.0266 \\
1.0236 \\
1.0206 \\
1.0177\end{array}$ & $\begin{array}{l}1.0290 \\
1.0260 \\
1.0230 \\
1.0200 \\
1.0171\end{array}$ & $\begin{array}{l}1.0284 \\
1.0254 \\
1.0224 \\
1.0194 \\
1.0165\end{array}$ & $\begin{array}{l}1.0278 \\
1.0248 \\
1.0218 \\
1.0189 \\
1.0159\end{array}$ & $\begin{array}{l}1.0272 \\
1.0242 \\
1.0212 \\
1.0183 \\
1.0153\end{array}$ \\
\hline $\begin{array}{l}500 \\
600 \\
700 \\
800 \\
900\end{array}$ & $\begin{array}{l}1.0147 \\
1.0118 \\
1.0088 \\
1.0059 \\
1.0029\end{array}$ & $\begin{array}{l}1.0141 \\
1.0112 \\
1.0082 \\
1.0053 \\
1.0023\end{array}$ & $\begin{array}{l}1.0135 \\
1.0106 \\
1.0076 \\
1.0047 \\
1.0017\end{array}$ & $\begin{array}{l}1.0130 \\
1.0100 \\
1.0071 \\
1.0041 \\
1.0012\end{array}$ & $\begin{array}{l}1.0124 \\
1.0084 \\
1.0065 \\
1.0035 \\
1.0006\end{array}$ \\
\hline $\begin{array}{r}1,000 \\
100 \\
200 \\
300 \\
400 \\
\\
500 \\
600 \\
700 \\
800 \\
900\end{array}$ & $\begin{array}{r}1.0000 \\
.9971 \\
.9842 \\
.9912 \\
.9884 \\
\\
.9854 \\
.9826 \\
.9797 \\
.9768 \\
.9739\end{array}$ & $\begin{array}{l}.9994 \\
.9965 \\
.9936 \\
.9907 \\
.9878 \\
\\
.9849 \\
.9820 \\
.9791 \\
.9762 \\
.9734\end{array}$ & $\begin{array}{l}.9988 \\
.9959 \\
.9930 \\
.9901 \\
.9872 \\
\\
.9843 \\
.9814 \\
.9785 \\
.9757 \\
.9728\end{array}$ & $\begin{array}{l}.9982 \\
.9953 \\
.9924 \\
.9895 \\
.9866 \\
\\
.9837 \\
.9808 \\
.9780 \\
.9751 \\
.9722\end{array}$ & $\begin{array}{l}.9977 \\
.9847 \\
.9918 \\
.9889 \\
.9860 \\
\\
.9831 \\
.9803 \\
.9774 \\
.9745 \\
.9716\end{array}$ \\
\hline $\begin{array}{r}2,000 \\
100 \\
200 \\
300 \\
400 \\
500 \\
600 \\
700 \\
800 \\
900\end{array}$ & $\begin{array}{l}.9711 \\
.9682 \\
.9654 \\
.9625 \\
.9597\end{array}$ & $\begin{array}{r}.9705 \\
.9676 \\
.9648 \\
.9619 \\
.9591\end{array}$ & $\begin{array}{l}.9699 \\
.9671 \\
.9642 \\
.9614 \\
.9585\end{array}$ & $\begin{array}{l}.9551 \\
.9523 \\
.9495 \\
.9467 \\
.9439\end{array}$ & $\begin{array}{l}.9688 \\
.9659 \\
.9631 \\
.9602 \\
.9574 \\
\\
.9546 \\
.9518 \\
.9489 \\
.9461 \\
.9433\end{array}$ \\
\hline $\begin{array}{r}3,000 \\
100 \\
200 \\
300 \\
400\end{array}$ & $\begin{array}{l}.9428 \\
.9400 \\
.9372 \\
.9344 \\
.9316\end{array}$ & $\begin{array}{l}.9422 \\
.9394 \\
.9366 \\
.9339 \\
.9311\end{array}$ & $\begin{array}{l}.9417 \\
.9389 \\
.9361 \\
.9333 \\
.9305\end{array}$ & $\begin{array}{l}.9411 \\
.9383 \\
.9355 \\
.9327 \\
.8300\end{array}$ & $\begin{array}{l}.9405 \\
.9377 \\
.9350 \\
.9322 \\
.9294\end{array}$ \\
\hline $\begin{array}{r}4,000 \\
100 \\
200 \\
300 \\
400\end{array}$ & $\begin{array}{l}.9151 \\
.9124 \\
.9097 \\
.9069 \\
.9042\end{array}$ & $\begin{array}{l}.9146 \\
.9118 \\
.9081 \\
.9064 \\
.9037\end{array}$ & $\begin{array}{l}.9140 \\
.9113 \\
.9086 \\
.9059 \\
.9031\end{array}$ & $\begin{array}{l}.9135 \\
.9107 \\
.9080 \\
.9053 \\
.9026\end{array}$ & $\begin{array}{l}.9129 \\
.9102 \\
.9075 \\
.9048 \\
.9021\end{array}$ \\
\hline $\begin{array}{l}500 \\
600 \\
700 \\
800 \\
900\end{array}$ & $\begin{array}{l}.9015 \\
.8988 \\
.8961 \\
.8934 \\
.8908\end{array}$ & $\begin{array}{l}.9010 \\
.8983 \\
.8956 \\
.8929 \\
.8902\end{array}$ & $\begin{array}{l}.8004 \\
.8977 \\
.8951 \\
.8924 \\
.8897\end{array}$ & $\begin{array}{l}.8999 \\
.8972 \\
.8945 \\
.8918 \\
.8892\end{array}$ & $\begin{array}{l}.8994 \\
.8967 \\
.8940 \\
.8913 \\
.8886\end{array}$ \\
\hline
\end{tabular}

\begin{tabular}{|c|c|c|c|c|c|}
\hline $\begin{array}{l}\text { Mean } \\
\text { Altimeter } \\
\text { Reading }\end{array}$ & 0 & 20 & 40 & 60 & 80 \\
\hline $\begin{array}{r}5,000 \\
100 \\
200 \\
300 \\
400\end{array}$ & $\begin{array}{r}0.8881 \\
.8854 \\
.8828 \\
.8801 \\
.8774\end{array}$ & $\begin{array}{r}0.8875 \\
.8849 \\
.8822 \\
.8796 \\
.8769\end{array}$ & $\begin{array}{r}0.8870 \\
.8844 \\
.8817 \\
.8790 \\
.8764\end{array}$ & $\begin{array}{r}0.8865 \\
.8838 \\
.8812 \\
.8785 \\
.8759\end{array}$ & $\begin{array}{r}0.8860 \\
.8833 \\
.8806 \\
.8780 \\
.8753\end{array}$ \\
\hline $\begin{array}{l}500 \\
600 \\
700 \\
800 \\
900\end{array}$ & $\begin{array}{l}.8748 \\
.8722 \\
.8695 \\
.8669 \\
.8643\end{array}$ & $\begin{array}{l}.8743 \\
.8716 \\
.8690 \\
.8664 \\
.8638\end{array}$ & $\begin{array}{l}.8737 \\
.8711 \\
.8685 \\
.8659 \\
.8632\end{array}$ & $\begin{array}{l}.8732 \\
.8706 \\
.8680 \\
.8653 \\
.8627\end{array}$ & $\begin{array}{l}.8727 \\
.8701 \\
.8674 \\
.8648 \\
.8622\end{array}$ \\
\hline $\begin{array}{r}6,000 \\
100 \\
200 \\
300 \\
400\end{array}$ & $\begin{array}{l}.8617 \\
.8591 \\
.8565 \\
.8539 \\
.8513\end{array}$ & $\begin{array}{l}.8611 \\
.8585 \\
.8559 \\
.8533 \\
.8508\end{array}$ & $\begin{array}{l}.8606 \\
.8580 \\
.8554 \\
.8528 \\
.8502\end{array}$ & $\begin{array}{l}.8601 \\
.8575 \\
.8549 \\
.8523 \\
.8497\end{array}$ & $\begin{array}{l}.8596 \\
.8570 \\
.8544 \\
.8518 \\
.8492\end{array}$ \\
\hline $\begin{array}{l}500 \\
600 \\
700 \\
800 \\
900\end{array}$ & $\begin{array}{l}.8487 \\
.8461 \\
.8435 \\
.8410 \\
.8384\end{array}$ & $\begin{array}{l}.8482 \\
.8456 \\
.8430 \\
.8405 \\
.8379\end{array}$ & $\begin{array}{l}.8477 \\
.8451 \\
.8425 \\
.8399 \\
.8374\end{array}$ & $\begin{array}{l}.8471 \\
.8446 \\
.8420 \\
.8394 \\
.8369\end{array}$ & $\begin{array}{l}.8466 \\
.8441 \\
.8415 \\
.8389 \\
.8364\end{array}$ \\
\hline $\begin{array}{r}7,000 \\
100 \\
200 \\
300 \\
400\end{array}$ & $\begin{array}{l}.8359 \\
.8333 \\
.8308 \\
.8282 \\
.8257\end{array}$ & $\begin{array}{l}.8354 \\
.8328 \\
.8303 \\
.8277 \\
.8252\end{array}$ & $\begin{array}{r}.8348 \\
.8323 \\
.8298 \\
.8272 \\
8247\end{array}$ & $\begin{array}{l}.8343 \\
.8318 \\
.8292 \\
.8267 \\
.8242\end{array}$ & $\begin{array}{l}.8338 \\
.8313 \\
.8287 \\
.8262 \\
.8237\end{array}$ \\
\hline $\begin{array}{l}500 \\
600 \\
700 \\
800 \\
800\end{array}$ & $\begin{array}{l}.8232 \\
.8207 \\
.8181 \\
.8156 \\
.8131\end{array}$ & $\begin{array}{l}.8227 \\
.8202 \\
.8176 \\
.8151 \\
.8126\end{array}$ & $\begin{array}{l}.8222 \\
.8197 \\
.8171 \\
.8146 \\
.8121\end{array}$ & $\begin{array}{l}.8217 \\
.8191 \\
.8166 \\
.8141 \\
.8116\end{array}$ & $\begin{array}{l}.8212 \\
.8186 \\
.8161 \\
.8136 \\
.8111\end{array}$ \\
\hline $\begin{array}{r}8,000 \\
100 \\
200 \\
300 \\
400\end{array}$ & $\begin{array}{l}.8106 \\
.8082 \\
.8057 \\
.8032 \\
.8007\end{array}$ & $\begin{array}{l}.8101 \\
.8077 \\
.8052 \\
.8027 \\
.8002\end{array}$ & $\begin{array}{l}.8096 \\
.8072 \\
.8047 \\
.8022 \\
.7997\end{array}$ & $\begin{array}{l}.8091 \\
.8067 \\
.8042 \\
.8017 \\
.7992\end{array}$ & $\begin{array}{l}.8086 \\
.8062 \\
.8037 \\
.8012 \\
.7988\end{array}$ \\
\hline $\begin{array}{l}500 \\
600 \\
700 \\
800 \\
900\end{array}$ & $\begin{array}{l}.7983 \\
.7958 \\
.7938 \\
.7909 \\
.7884\end{array}$ & $\begin{array}{l}.7978 \\
.7953 \\
.7928 \\
.7904 \\
.7880\end{array}$ & $\begin{array}{l}.7973 \\
.7948 \\
.7924 \\
.7899 \\
.7875\end{array}$ & $\begin{array}{r}.7968 \\
.7943 \\
.7919 \\
.7894 \\
.7870\end{array}$ & $\begin{array}{l}.7963 \\
.7938 \\
.7914 \\
.7889 \\
.7865\end{array}$ \\
\hline $\begin{array}{r}8,000 \\
100 \\
200 \\
300 \\
400\end{array}$ & $\begin{array}{l}.7860 \\
.7836 \\
.7812 \\
.7787 \\
.7783\end{array}$ & $\begin{array}{l}.7855 \\
.7831 \\
.7807 \\
.7783 \\
.7758\end{array}$ & $\begin{array}{l}.7850 \\
.7826 \\
.7802 \\
.7778 \\
.7754\end{array}$ & $\begin{array}{l}.7846 \\
.7821 \\
.7797 \\
.7773 \\
.7749\end{array}$ & $\begin{array}{l}.7841 \\
.7816 \\
.7792 \\
.7768 \\
.7744\end{array}$ \\
\hline $\begin{array}{l}500 \\
600 \\
700 \\
800 \\
900\end{array}$ & $\begin{array}{l}.7739 \\
.7715 \\
.7691 \\
.7667 \\
.7643\end{array}$ & $\begin{array}{l}.7734 \\
.7710 \\
.7686 \\
.7663 \\
.7639\end{array}$ & $\begin{array}{l}.7730 \\
.7706 \\
.7682 \\
.7658 \\
.7634\end{array}$ & $\begin{array}{l}.7725 \\
.7701 \\
.7677 \\
.7653 \\
.7629\end{array}$ & $\begin{array}{l}.7720 \\
.7696 \\
.7672 \\
.7648 \\
.7624\end{array}$ \\
\hline
\end{tabular}

\begin{tabular}{|c|c|c|c|c|c|}
\hline $\begin{array}{c}\text { Mean } \\
\text { Altimeter } \\
\text { Reading }\end{array}$ & 0 & 20 & 40 & 60 & 80 \\
\hline $\begin{array}{r}10,000 \\
100 \\
200 \\
300 \\
400\end{array}$ & $\begin{array}{r}0.7620 \\
.7596 \\
.7572 \\
.7549 \\
.7525\end{array}$ & $\begin{array}{r}0.7615 \\
.7591 \\
.7567 \\
.7544 \\
.7520\end{array}$ & $\begin{array}{r}0.7610 \\
.7586 \\
.7563 \\
.7539 \\
.7516\end{array}$ & $\begin{array}{r}0.7605 \\
.7582 \\
.7558 \\
.7534 \\
.7511\end{array}$ & $\begin{array}{r}0.7601 \\
.7577 \\
.7553 \\
.7530 \\
.7506\end{array}$ \\
\hline $\begin{array}{l}500 \\
600 \\
700 \\
800 \\
900\end{array}$ & $\begin{array}{l}.7502 \\
.7478 \\
.7455 \\
.7431 \\
.7408\end{array}$ & $\begin{array}{l}.7497 \\
.7473 \\
.7450 \\
.7427 \\
.7403\end{array}$ & $\begin{array}{l}.7492 \\
.7469 \\
.7445 \\
.7422 \\
.7399\end{array}$ & $\begin{array}{l}.7487 \\
.7464 \\
.7441 \\
.7417 \\
.7394\end{array}$ & $\begin{array}{l}.7483 \\
.7459 \\
.7436 \\
.7413 \\
.7389\end{array}$ \\
\hline $\begin{array}{r}11,000 \\
100 \\
200 \\
300 \\
400\end{array}$ & $\begin{array}{l}.7385 \\
.7362 \\
.7338 \\
.7315 \\
.7292\end{array}$ & $\begin{array}{l}.7380 \\
.7357 \\
.7334 \\
.7311 \\
.7288\end{array}$ & $\begin{array}{l}.7376 \\
.7352 \\
.7329 \\
.7306 \\
.7283\end{array}$ & $\begin{array}{l}.7371 \\
.7348 \\
.7325 \\
.7302 \\
.7279\end{array}$ & $\begin{array}{l}.7366 \\
.7343 \\
.7320 \\
.7297 \\
.7274\end{array}$ \\
\hline $\begin{array}{l}500 \\
600 \\
700 \\
800 \\
900\end{array}$ & $\begin{array}{l}.7269 \\
.7246 \\
.7224 \\
.7201 \\
.7178\end{array}$ & $\begin{array}{l}.7265 \\
.7242 \\
.7219 \\
.7196 \\
.7174\end{array}$ & $\begin{array}{l}.7260 \\
.7237 \\
.7215 \\
.7192 \\
.7169\end{array}$ & $\begin{array}{l}.7256 \\
.7233 \\
.7210 \\
.7187 \\
.7165\end{array}$ & $\begin{array}{l}.7251 \\
.7228 \\
.7205 \\
.7183 \\
.7160\end{array}$ \\
\hline $\begin{array}{r}12,000 \\
100 \\
200 \\
300 \\
400 \\
\\
500 \\
600 \\
700 \\
800 \\
900\end{array}$ & $\begin{array}{l}.7156 \\
.7133 \\
.7110 \\
.7088 \\
.7065 \\
.7043 \\
.7021 \\
.6998 \\
.6976 \\
.6954\end{array}$ & $\begin{array}{l}.7151 \\
.7128 \\
.7106 \\
.7083 \\
.7061 \\
\\
.7038 \\
.7016 \\
.6994 \\
.6972 \\
.6949\end{array}$ & $\begin{array}{l}.7146 \\
.7124 \\
.7101 \\
.7079 \\
.7056 \\
.7034 \\
.7012 \\
.6989 \\
.6967 \\
.6945\end{array}$ & $\begin{array}{l}.7142 \\
.7119 \\
.7097 \\
.7074 \\
.7052 \\
\\
.7030 \\
.7007 \\
.6985 \\
.6963 \\
.6941\end{array}$ & $\begin{array}{l}.7137 \\
.7115 \\
.7092 \\
.7070 \\
.7047 \\
.7025 \\
.7003 \\
.6980 \\
.6958 \\
.6836\end{array}$ \\
\hline $\begin{array}{r}13,000 \\
100 \\
200 \\
300 \\
400 \\
500 \\
600 \\
700 \\
800 \\
900\end{array}$ & $\begin{array}{l}.6932 \\
.6910 \\
.6888 \\
.6866 \\
.6844\end{array}$ & $\begin{array}{l}.6927 \\
.6905 \\
.6883 \\
.6861 \\
.6839\end{array}$ & $\begin{array}{l}.6923 \\
.6901 \\
.6879 \\
.6857 \\
.6835\end{array}$ & $\begin{array}{l}.6918 \\
.6896 \\
.6874 \\
.6852 \\
.6831\end{array}$ & $\begin{array}{l}.6914 \\
.6892 \\
.6870 \\
.6848 \\
.6826 \\
\\
.6804 \\
.6783 \\
.6761 \\
.6739 \\
.6718\end{array}$ \\
\hline $\begin{array}{r}14,000 \\
100 \\
200 \\
300 \\
400\end{array}$ & $\begin{array}{l}.6713 \\
.6692 \\
.6670 \\
.6649 \\
.6627\end{array}$ & $\begin{array}{l}.6709 \\
.6688 \\
.6686 \\
.6645 \\
.6623\end{array}$ & $\begin{array}{l}.6705 \\
.6683 \\
.6662 \\
.6640 \\
.6619\end{array}$ & $\begin{array}{l}.6700 \\
.6679 \\
.6657 \\
.6636 \\
.6615\end{array}$ & $\begin{array}{l}.6696 \\
.6675 \\
.6653 \\
.6632 \\
.6610\end{array}$ \\
\hline $\begin{array}{l}500 \\
600 \\
700 \\
800 \\
900\end{array}$ & $\begin{array}{l}.6606 \\
.6585 \\
.6564 \\
.6542 \\
.6521\end{array}$ & $\begin{array}{l}.6602 \\
.6581 \\
.6559 \\
.6538 \\
.6517\end{array}$ & $\begin{array}{l}.6598 \\
.6576 \\
.6555 \\
.6534 \\
.6513\end{array}$ & $\begin{array}{l}.6593 \\
.6572 \\
.6551 \\
.6530 \\
.6509\end{array}$ & $\begin{array}{l}.6588 \\
.6588 \\
.6547 \\
.6526 \\
.6504\end{array}$ \\
\hline
\end{tabular}

Proportional Parts

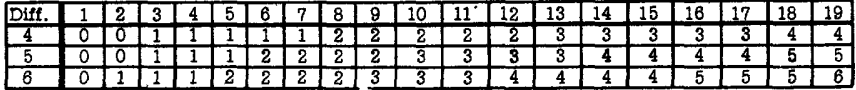




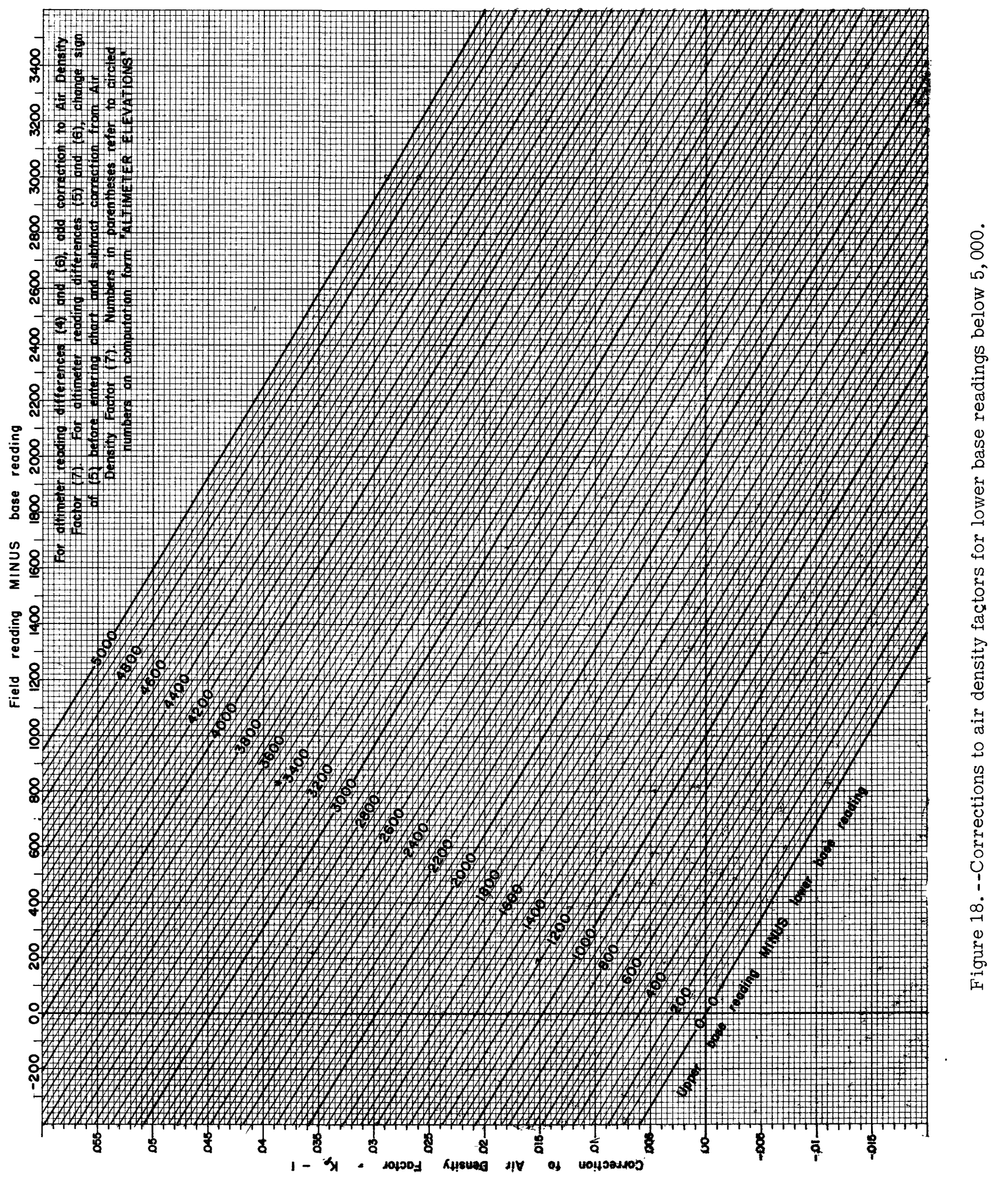




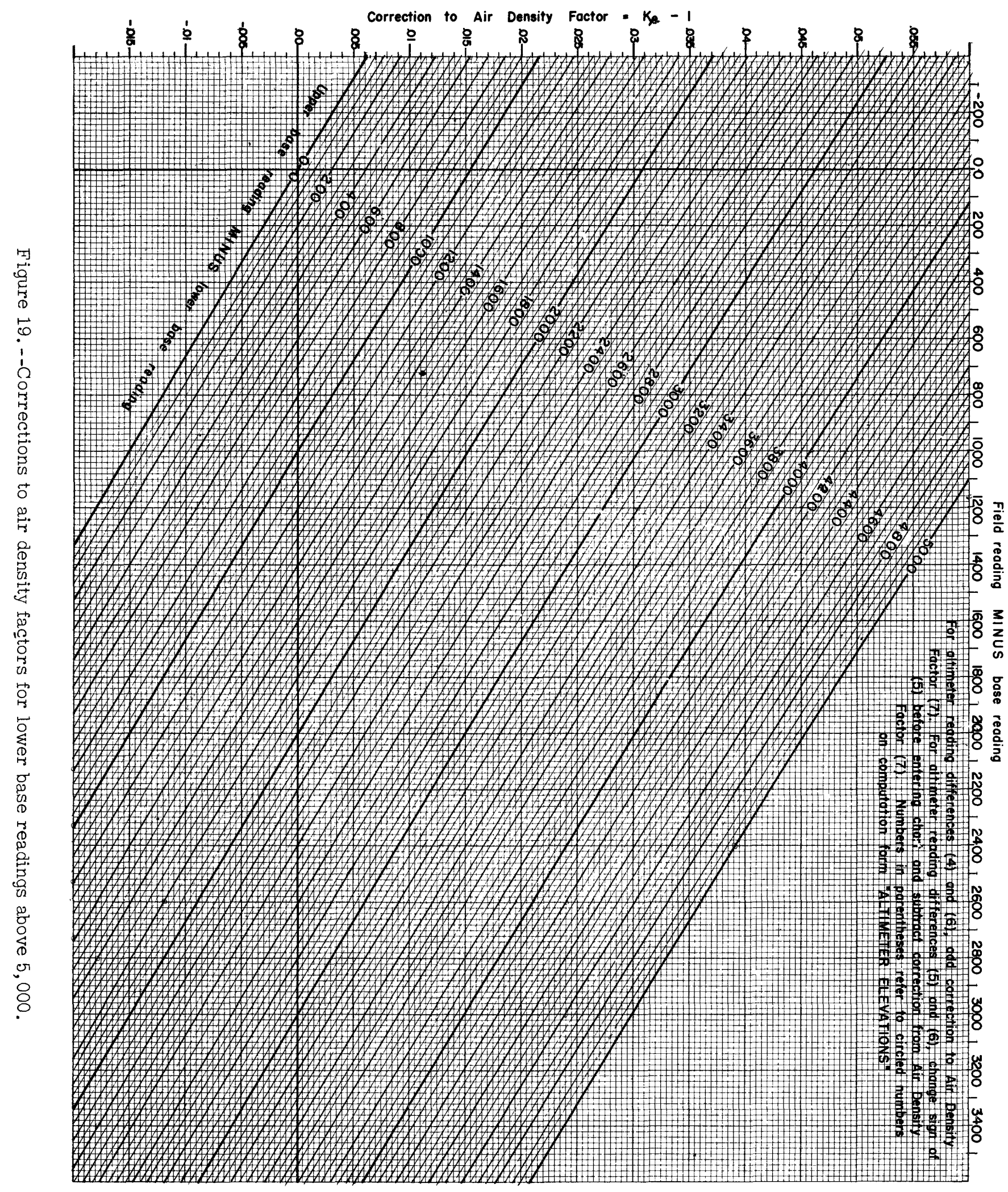




\section{Graphical Evaluation of $\mathrm{b}=\mathrm{K}_{\mathrm{p}}-1$}

To illustrate the use of the graph, the values used in the above numerical computation of $\mathrm{K}$ will be employed.

For evaluation from lower base

$$
\begin{array}{ll}
(4)=1343 \quad(6)=1592.5
\end{array}
$$

On the graph, a point which has the abscissa value $(4)=1343$ and which would be on a diagonal straight line represented by $(6)=1592.5$ is situated just under the line $(6)=1600$. It will be found from the graph that the ordinate value $(b)$ is 0.0035 . The value $0.0035+1=K_{p}$ is found to be the same as the one obtained by the numerical computation. Computation of altitude determination by the use of value $b$.

$$
\begin{aligned}
& \text { Elev }=I+(4)(7) . \quad \text { (See computation form }) \\
& \begin{aligned}
(7)^{\prime} & =(7)+b . \text { Substitute }(7)^{\prime} \text { for }(7) \text { in the equation above } \\
\text { Elev } & =I+(4)[(7)+b]=681.7-(1343)(1.0289+0.0035) \\
\text { Elev } & =681.7+1343(1+0.0324) \\
& =681.7+1386.5 \\
& =2068.2 \text { feet }
\end{aligned}
\end{aligned}
$$

By numerical computation: 2068.4 feet

For evaluation from upper base

$$
\begin{array}{ll}
(5)=-249.5 & (6)=1592.5
\end{array}
$$

On the graph, a point which has the abscissa value $(5)=-249.5$ (a1sregard the sign of this value for evaluation purposes) and which would be on a diagonal straight line represented by $(6)=1592.5$ we find the value $b$ to be 0.0202 . Because the value of (5) has a negative sign this value must be subtracted from (7).

Computation of altitude determination from upper base by use of value b (check computation).

$$
\begin{aligned}
& \text { Elev }=(5)(7)-\text { II } \\
& \begin{aligned}
(7)^{\prime} & =(7)-\mathrm{b} \text { Substitute }(7)^{\prime} \text { for }(7) \text { in the equation above } \\
\text { Elev } & =\text { II }-(5) \quad[(7)-\mathrm{b}]=2320.2-249.5(1.0289-0.0202) \\
\text { Elev } & =2320.2-249.5(1.0087) \\
& =2320.2-251.7 \\
& =2068.5 \text { feet }
\end{aligned}
\end{aligned}
$$

Summary of results of altitude determinations of Station N-251: Known elevation; 2077.9 


\section{Computations from lower base \\ (feet)}

USGS Form 2063.5

From table 2068.4

From graph 2068.2
Computations from upper base (feet)

2063.5

2068.6

2068.5

The error of an altitude determination is usually considerably reduced when the tilt of the equal-pressure surfaces over the survey area is taken into account. 


\section{PRECISION ALTIGRAMS}

Figure 20 shows sections of altigrams taken in the same room at the same time on two United Geophysical electronic altigraphs. The upper record was made by altigraph 14, and the lower record (superimposed on the same time scale as the upper graph) was made by altigraph 15 . Each vertical division represents 1 foot of altitude, and each horizontal division represents 1 minute of time. The altigraphs recorded an altitude reading every 2 seconds.

Atmospheric conditions were ideal, with the pressure remaining constant within about 2 feet of the average for a period of $13 / 4$ hours. However, local disturbances caused variations in altitude readings as great as 3 feet in 30 seconds. Such disturbances obviously can cause errors in comparing instruments or in taking field readings.

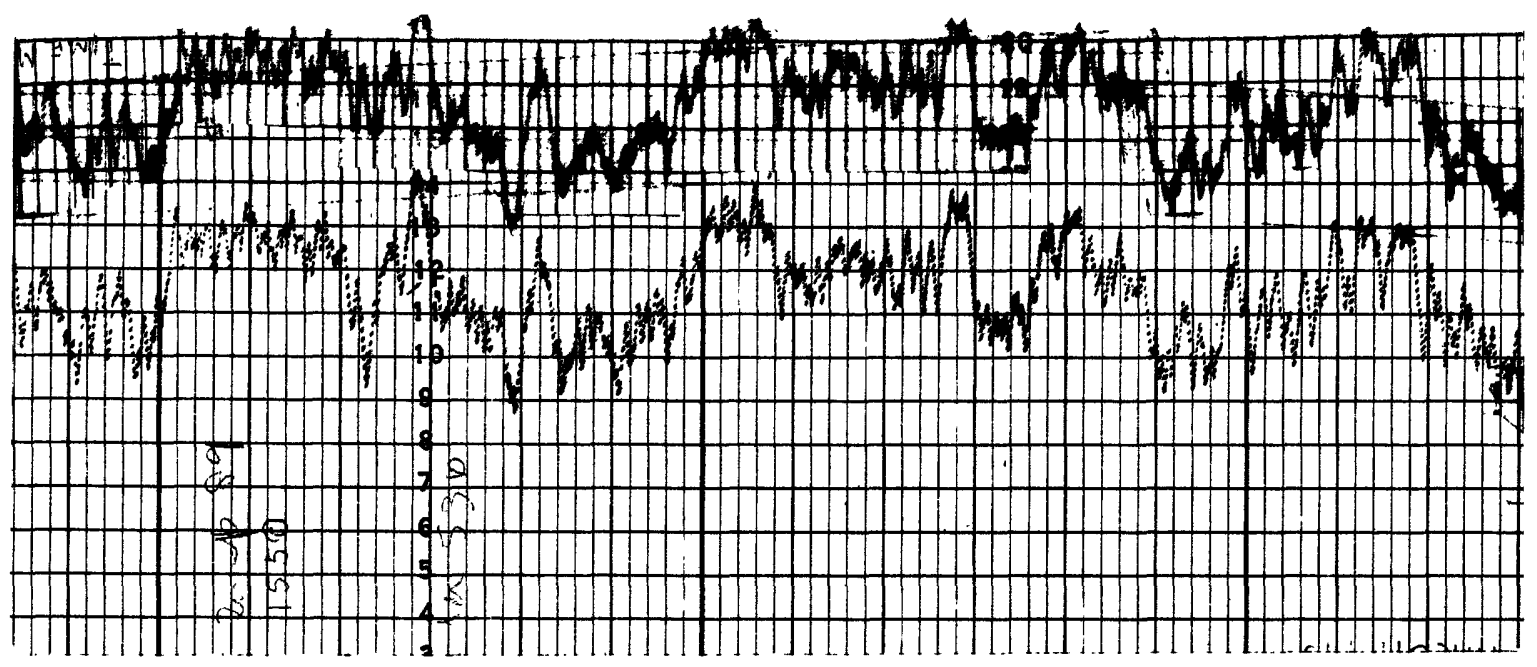

Figure 20. --Electronic altigraph records. 


\section{A METHOD FOR CALIBRATING ALTIMETERS}

A method developed and formerly used by the Topographic Division of the Geological Survey for calibrating altimeters consists in comparing sets of six or more altimeters. The altimeters are placed in a test chamber, and the pressure is reduced in steps to give instrument readings approximately at even 100 -foot altitude intervals. The pressure is held as nearly constant as possible while all the instruments in the set are read. Readings are taken at each successive interval to the upper altitude limit of the altimeters' range, and then similar sets of readings are taken as the pressure is increased to the lower altitude limit. For each set of readings at each pressure step, the correct value is assumed to be the average of the individual readings, and the error for each altimeter is the difference between its reading and the average. Each calibration thus gives two tabulations of averages and errors, one obtained with altitude increasing and the other obtained with altitude decreasing. Comparison of the two tabulations provides some indication of the hysteresis and hence the reliability of each altimeter. The pair of average values for each step is then averaged to obtain the final accepted value, and a correction curve is plotted for each altimeter. The main weakness of this method of calibration is that it operates on a comparative rather than an absolute basis; the errors of the poorer instruments are given full weight in obtaining the averages. Moreover, this method indicates relative rather than absolute hysteresis. 


\section{STRAIN IN FLEXURAL ELEMENTS}

A simplified method of computing the maximum safe strain in a flexural element can be used if the minimum radius of curvature to which the element is flexed can be determined. In figure 21 the neutral axis or unstressed part of the section is, for practical purposes, at its center. The maximum strain, which occurs at the inner and outer surfaces, is equal to $(t / 2) / R$. For beryllium copper, we assume a classified yield stress of 100,000 psi and a maximum safe stress of 30,000 psi for use in altimeter flexural elements. The modulus of elasticity, or ratio of stress to strain, is $18,000,000$. The permissible strain is therefore $30,000 / 18,000,000=1 / 600$.

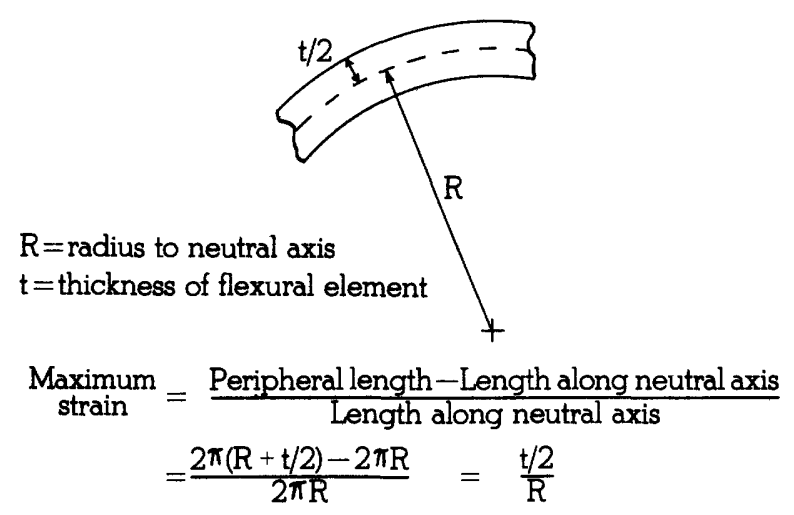

Figure 21. --Strain in curved flexural element.

$$
\text { Strain }=\frac{t / 2}{R}=\frac{1}{600} \text {, and } \max \frac{t}{R}=\frac{1}{300}
$$

For beryllium copper, then, the minimum radius of curvature for a normally uncurved flexural element should be no less than 300 times the thickness of the element. These limits may be exceeded under some conditions; for example, if a flexural element has very small effect on vacuum-box displacement, a slightly higher stress can be tolerated. However, care must be exercised in designing for higher stresses because the elastic effects at a stress of 40,000 psi are about 4 times as large as those at $30,000 \mathrm{psi}$. For a large elastic member, such as a loading spring, the stress limit of 30,000 psi may be somewhat excessive.

Sometimes, of course, it is necessary to use standard engineering beam formulas or spring tables and formulas in designing flexural elements for stress and strain. 